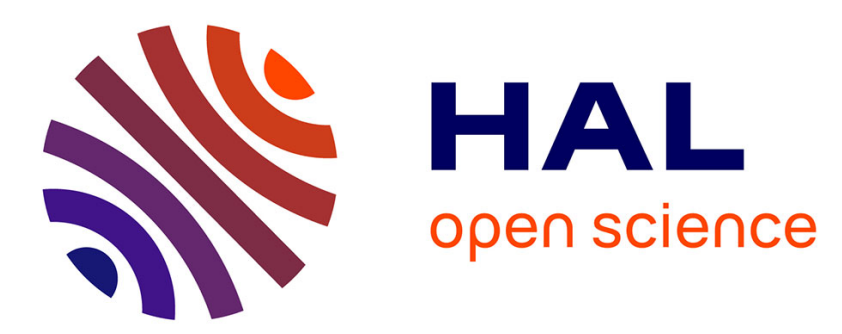

\title{
The Pt-Catalyzed Ethylene Hydroamination by Aniline: A Computational Investigation of the Catalytic Cycle
} Pavel Dub, Rinaldo Poli

\section{To cite this version:}

Pavel Dub, Rinaldo Poli. The Pt-Catalyzed Ethylene Hydroamination by Aniline: A Computational Investigation of the Catalytic Cycle. Journal of the American Chemical Society, 2010, 132 (39), pp.13799-13812. 10.1021/ja1051654 . hal-03177581

\section{HAL Id: hal-03177581 \\ https://hal.science/hal-03177581}

Submitted on 23 Mar 2021

HAL is a multi-disciplinary open access archive for the deposit and dissemination of scientific research documents, whether they are published or not. The documents may come from teaching and research institutions in France or abroad, or from public or private research centers.
L'archive ouverte pluridisciplinaire HAL, est destinée au dépôt et à la diffusion de documents scientifiques de niveau recherche, publiés ou non, émanant des établissements d'enseignement et de recherche français ou étrangers, des laboratoires publics ou privés. 


\title{
The Pt-catalyzed ethylene hydroamination by aniline: a Computational Investigation of the Catalytic Cycle
}

\author{
Pavel A. Dub and Rinaldo Poli*,a,b
}

${ }^{a}$ CNRS; LCC (Laboratoire de Chimie de Coordination); Université de Toulouse; UPS, INP; F31077 Toulouse, France ; 205, route de Narbonne, F-31077 Toulouse, France; Fax: (+) 33561553003; E-mail:poli@lcc-toulouse.fr

${ }^{b}$ Institut Universitaire de France, 103, bd Saint-Michel, 75005 Paris, France 


\section{Summary}

A full QM DFT study without system simplification and with the inclusion of solvation effects in aniline as solvent has addressed the addition of aniline to ethylene catalyzed by $\mathrm{PtBr}_{2} / \mathrm{Br}^{-}$. The resting state of the catalytic cycle is the $\left[\mathrm{PtBr}_{3}\left(\mathrm{C}_{2} \mathrm{H}_{4}\right)\right]^{-}$complex (II). A cycle involving aniline activation by N-H oxidative addition was found energetically prohibitive. The operating cycle involves ethylene activation followed by nucleophilic addition of aniline to the coordinated ethylene, intramolecular transfer of the ammonium proton to the metal center to generate a 5coordinate (16- electron) $\mathrm{Pt}^{\mathrm{IV}}-\mathrm{H}$ intermediate, and final reductive elimination of the PhNHEt product. Several low energy ethylene complexes, namely trans- and cis- $\mathrm{PtBr}_{2}\left(\mathrm{C}_{2} \mathrm{H}_{4}\right)\left(\mathrm{PhNH}_{2}\right)$ (IV and V) and trans- and cis- $\mathrm{PtBr}_{2}\left(\mathrm{C}_{2} \mathrm{H}_{4}\right)_{2}$ (VII and VIII) are susceptible to aniline nucleophilic addition to generate zwitterionic intermediates. However, only $\left[\mathrm{PtBr}_{3} \mathrm{CH}_{2} \mathrm{CH}_{2} \mathrm{NH}_{2} \mathrm{Ph}\right]^{-}(\mathbf{I X})$ derived from $\mathrm{PhNH}_{2}$ addition to II is the productive intermediate. It easily transfers a proton to the Pt atom to yield $\left[\mathrm{PtHBr}_{3}\left(\mathrm{CH}_{2} \mathrm{CH}_{2} \mathrm{NHPh}\right)\right]^{-}(\mathbf{X X})$, which leads to rate-determining $\mathrm{C}-\mathrm{H}$ reductive elimination through transition state $\mathbf{T S}(\mathbf{X X}-\mathbf{L})$ with formation of the $\sigma$-complex $\left[\mathrm{PtBr}_{3}\left(\mathrm{k}^{2}: C, H-\mathrm{HCH}_{2} \mathrm{CH}_{2} \mathrm{NHPh}\right)\right]^{-}(\mathbf{L})$, from which the product can be liberated via ligand substitution by a new $\mathrm{C}_{2} \mathrm{H}_{4}$ molecule to regenerate II. Saturated (18-electron) $\mathrm{Pt}^{\mathrm{IV}}$ hydride complexes obtained by ligand addition or by chelation of the aminoalkyl ligand liberate the product through higher energy pathways. Other pathways starting from the zwitterionic intermediates were also explored (intermolecular $\mathrm{N}$ deprotonation followed by $\mathrm{C}$ protonation or chelation to produce platina(II)azacyclobutane derivatives; intramolecular proton transfer from $\mathrm{N}$ to $\mathrm{C}$, either direct or assisted by an external aniline molecule) but all gave higher-energy intermediates or led to the same rate determining $\mathbf{T S}(\mathbf{X X}-\mathbf{L})$.

Keywords: platinum, homogeneous catalysis, hydroamination, non-activated olefins, DFT calculations 


\section{Introduction}

Hydroamination, the direct formation of a new C-N bond by addition of an $\mathrm{N}-\mathrm{H}$ bond across an unsaturated $\mathrm{CC}$ bond, currently attracts much interest in academia and industry. ${ }^{1-3}$ The intermolecular version of this process is still a great challenge, especially for non-activated olefins. Seminal work by Coulson showed that ethylene could be hydroaminated by a few highly basic secondary amines under forcing conditions with $\mathrm{RhCl}_{3}$ (or $\mathrm{IrCl}_{3}$ ) as catalyst. ${ }^{4}$, More recently, this system was found effective also for less basic amines such as aniline when modified by the addition of $n-\mathrm{Bu} 4 \mathrm{PI} / \mathrm{I}_{2}{ }^{6}$ Other relevant results for the intermolecular hydroamination of ethylene and other non activated olefins comprise the use of lanthanides, ${ }^{7,8}$ $\mathrm{Fe},{ }^{9} \mathrm{Ru},{ }^{10-12} \mathrm{Rh},{ }^{13} \mathrm{Ag},{ }^{14} \mathrm{Au},{ }^{15-18} \mathrm{Pd},{ }^{19,} 20$ and notably $\mathrm{Pt}^{21-23}$ Investigations initiated in our team by J.-J. Brunet have shown that $\mathrm{PtBr}_{2}$, in the presence of $n \mathrm{Bu}_{4} \mathrm{PX}(\mathrm{X}=$ halide $)$ as activator, is one of the most performing catalyst so far reported for the hydroamination of ethylene by weakly basic amines such as aniline and 2-chloroaniline (highest activity for $\mathrm{X}=\mathrm{Br}$; $\mathrm{TON}>150$ after $10 \mathrm{~h}$ at $150^{\circ} \mathrm{C}$ with $0.3 \mathrm{~mol} \%$ of Pt- precursor). ${ }^{24-27}$ Without a clear mechanistic understanding, however, it is difficult to imagine how to further improve the process efficiency for its potential application in bulk chemical manufacture.

Two alternative mechanisms are discussed in the literature, one starting with amine activation by $\mathrm{N}-\mathrm{H}$ oxidative addition and the other one based on amine nucleophilic addition to a coordinated olefin. The amine activation mechanism is mostly proposed for Rh- or Ir-based catalytic systems, ${ }^{28,}{ }^{29}$ whereas the olefin activation mechanism seems adopted by catalysts based on group $10^{30}$ and 11 metals. ${ }^{31}$ Senn and coworkers reported a computational study of the model $\mathrm{NH}_{3}$ addition to ethylene catalyzed by the $\left[\mathrm{MCl}\left(\mathrm{PH}_{3}\right)\left(\mathrm{C}_{2} \mathrm{H}_{4}\right)\right]^{\mathrm{zt}}$ complexes of Group $9(\mathrm{z}=0)$ and $10(\mathrm{z}=1)$ metals. $^{32}$ For the group 10 metals, for which only the olefin activation pathway has been explored, they found that the $\mathrm{NH}_{3}$ nucleophilic addition is thermodynamically and kinetically favourable and that the cleavage step is rate-determining (barrier of $34.9 \mathrm{kcal} \mathrm{mol}^{-1}$ 
for $\mathrm{Pt}$ ). On the other hand, Tsipis and Kefalidis, using the " $\mathrm{Pt}^{0}$ " model complex $\mathrm{Pt}\left(\mathrm{C}_{2} \mathrm{H}_{4}\right)\left(\mathrm{PH}_{3}\right)$, explored only the amine activation pathway, finding the reaction to be limited by the product reductive elimination step from the $\mathrm{Pt}^{\mathrm{II}}$ amido hydrido intermediate (barrier of $39.7 \mathrm{kcal} \mathrm{mol}^{-1}$ ). ${ }^{33}$ Other computational studies (e.g. on gold catalysis for diene hydroamination ${ }^{31}$ or palladium catalysis for the intermolecular hydroamination of vinylarenes ${ }^{34}$ and for the asymmetric intramolecular hydroamination of aminoalkenes ${ }^{35}$ ) have also explored solely the olefin activation mechanism. To the best of our knowledge, with the exception of the above mentioned study by Tsipis and Kefalidis and a study on iridium reported only in a Ph.D. thesis, ${ }^{36}$ studies of the N-H activation pathway have only been reported for alkaline-earths, ${ }^{37}$ early transition metals ${ }^{38-41}$ and the lanthanides. ${ }^{42-48}$

On the basis of known chemical transformations for related systems and on conventional wisdom, the Brunet Pt-based system was proposed to follow the ethylene activation pathway as shown in Scheme $1 .{ }^{26}$ However, whether the proton transfer from $\mathrm{N}$ to $\mathrm{C}$ from the zwitterionic intermediate occurs directly or via a Pt-hydride intermediate remained open to debate. The proton transfer process was considered as more facile from the anionic tribromo species $\left[\mathrm{PtBr}_{3}\left(\mathrm{CH}_{2} \mathrm{CH}_{2} \mathrm{NH}_{2} \mathrm{Ph}\right)\right]^{-}$because of the anticipated increased basicity, a hypothesis consistent with the observed activity enhancement when using a moderate excess amount of bromide salts. ${ }^{24}$

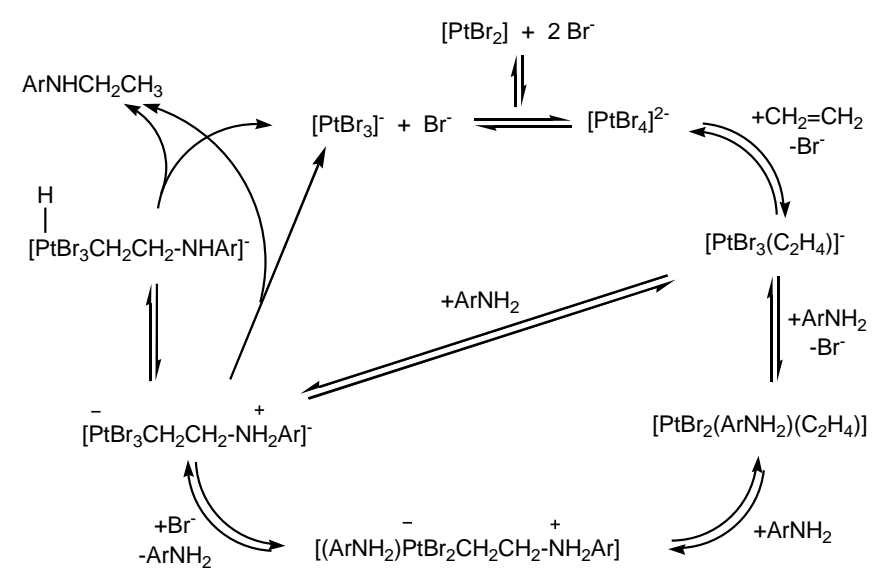


Scheme 1. Mechanism of $\mathrm{PtBr}_{2}$-catalyzed ethylene hydroamination by aniline as previously proposed. ${ }^{26}$

We have recently presented the synthesis, characterization, and equilibrium studies, backed up by DFT calculations, of a few $\mathrm{Pt}(\mathrm{II})$ complexes that are likely to be implicated in this $\mathrm{PtBr}_{2}-$ catalyzed process either as intermediates or as off-loop equilibrium species. ${ }^{49}$ Starting from $\mathrm{K}_{2} \mathrm{PtCl}_{4}$ or $\mathrm{KPtCl}_{3}\left(\mathrm{C}_{2} \mathrm{H}_{4}\right) \cdot \mathrm{H}_{2} \mathrm{O}$ (Zeise's salt), compounds $\left(n \mathrm{Bu}_{4} \mathrm{P}\right)_{2}\left[\mathrm{PtBr}_{4}\right](\mathbf{1}),\left(n \mathrm{Bu}_{4} \mathrm{P}\right)_{2}\left[\mathrm{Pt}_{2} \mathrm{Br}_{6}\right]$ (1'), $\left(n \mathrm{Bu}_{4} \mathrm{P}\right)\left[\mathrm{PtBr}_{3}\left(\mathrm{C}_{2} \mathrm{H}_{4}\right)\right](\mathbf{2}),\left(n \mathrm{Bu}_{4} \mathrm{P}\right)\left[\mathrm{PtBr}_{3}\left(\mathrm{PhNH}_{2}\right)\right](\mathbf{3})$, trans-[ $\left.\mathrm{PtBr}_{2}\left(\mathrm{C}_{2} \mathrm{H}_{4}\right)\left(\mathrm{PhNH}_{2}\right)\right]$ (4), cis$\left[\mathrm{PtBr}_{2}\left(\mathrm{C}_{2} \mathrm{H}_{4}\right)\left(\mathrm{PhNH}_{2}\right)\right]$ (5), and cis- $\left[\mathrm{PtBr}_{2}\left(\mathrm{PhNH}_{2}\right)_{2}\right]$ (6) have been isolated under different conditions in the presence of ethylene and aniline and fully characterized. The relative free energy of all species in solution under catalytic conditions has also been assessed from combined experimental and computational studies, showing that $\mathbf{2}$ is the most stable complex under catalytic conditions. The bis(ethylene) complexes trans- and cis- $\left[\mathrm{PtBr}_{2}\left(\mathrm{C}_{2} \mathrm{H}_{4}\right)_{2}\right](\mathbf{7}$ and $\mathbf{8})$ were not isolated (analogous $\left[\mathrm{PtCl}_{2}\left(\mathrm{C}_{2} \mathrm{H}_{4}\right)_{2}\right]$ complexes have previously been described ${ }^{50-52}$ ), but the calculations show their energetic accessibility under catalytic conditions. Therefore, all abovementioned $\mathrm{Pt}^{\mathrm{II}}$-ethylene species are qualified candidates for the nucleophilic attack by aniline and need to be considered for the subsequent steps of the catalytic cycle because they are all present in equilibrium concentrations according to their relative free energy. On the basis of these studies, the initial part of the catalytic cycle has been revised as shown in Scheme $2 .{ }^{49}$

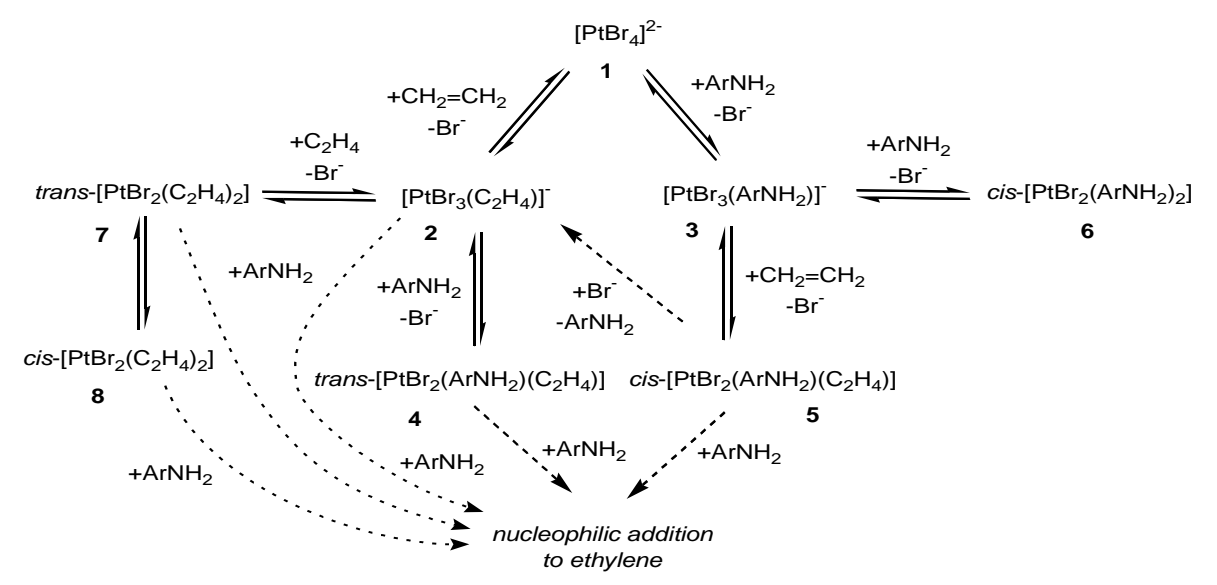


Scheme 2. Revised initial part of the $\mathrm{PtBr}_{2}$-catalyzed ethylene hydroamination mechanism. ${ }^{49}$

Attempts to experimentally observe zwitterionic intermediates failed, no reaction between complexes 2, 4 or $\mathbf{5}$ and aniline (other than ligand exchange for $\mathbf{2}$ and aniline self-exchange for 4) taking place under conditions suitable to NMR monitoring, which suggests either a high relative energy for these zwitterionic complexes or a high nucleophilic addition barrier. ${ }^{49}$ Since the identity of the proposed intermediates after nucleophilic addition could not be verified experimentally, we have recurred to the computational method to elucidate the remaining mechanistic details of this catalytic cycle. The above-mentioned computational investigation using complex $\left[\mathrm{PtCl}\left(\mathrm{PH}_{3}\right)_{2}\right]^{+}$as a model for the catalyst and $\mathrm{NH}_{3}$ for the amine ${ }^{32}$ cannot be extrapolated to the Brunet catalytic system, because the nature of the amine (in particularly its basicity) plays a determining role in the nucleophilic addition energetics and because the Brunet system was shown to be activated by excess bromide, which would be incompatible with the presence of electronically unsaturated cationic species, and to be poisoned by the presence of 2 equivalents of a phosphine ligand. ${ }^{24,53}$ Therefore, our computational investigation was accomplished on the real catalytic system. As mentioned above, the $\mathrm{PtX}_{2} / \mathrm{X}^{-}$system was found most active for $\mathrm{X}=\mathrm{Br}$. Therefore, the calculations are restricted to this halide. An investigation of how the energetics of the catalytic cycle is affected by the nature of $\mathrm{X}$ is planned for the near future.

\section{Computational Details}

All geometry optimizations were carried out by the DFT approach with the Gaussian03 suite of programs ${ }^{54}$ using the B3LYP functional. ${ }^{55-57}$ In spite of a few problems pointed out for this functional, ${ }^{58}$ it was selected because it remains one of the most popular functionals used in transition metal computational chemistry. One of the apparent problems is an overestimation of 
spin polarization, but all molecules described in this work are diamagnetic with the paramagnetic excited states expected at much higher energy, thus the RHF description is appropriate. All atoms except Pt were described by the standard $6-31+\mathrm{G}^{*}$ basis set, which includes both polarization and diffuse functions that are necessary to allow angular and radial flexibility to the highly anionic systems. The Pt atom was described by the LANL2TZ(f) basis, which is an uncontracted version of LANL2DZ and includes an $\mathrm{f}$ polarization function and an ECP. ${ }^{59}$ The geometry optimizations were carried out on isolated molecules in the gas phase. Frequency calculations were carried out for all optimized geometries in order to verify their nature as local minima, for the calculation of thermodynamic parameters at $298.15 \mathrm{~K}$ and at $423.15 \mathrm{~K}$ under the ideal gas and harmonic approximations, and for the identification of all transition states (one imaginary frequency). Solvent effects were introduced by means of C-PCM ${ }^{60,61}$ single point calculations on the gas-phase optimized geometries in aniline $(\varepsilon=6.89)$, which was considered to best approximate the reaction solvent. Among various continuum solvent models, the C-PCM was selected because of its generally better performance, ${ }^{62-64}$ even though there remains an inherent error when working with charged species. ${ }^{62}$ The solvent cavity was created by a series of overlapping spheres by the default UA0 model (or SPHEREONH for the delocalised proton atoms) and all standard settings as implemented in Gaussian03 were used for the C-PCM calculations. The reaction free-energy changes in solution were corrected for the change of standard state from the gas phase $(1 \mathrm{~atm})$ to solution $(1 \mathrm{M}) .{ }^{65}$ The approach of optimizing the geometries in the gas phase and then keeping the geometry frozen for the C-PCM calculation was preferred because of the known convergence problems of the geometry optimization in the presence of the C-PCM, especially for molecules containing weak interaction (i.e. hydrogen bonds). The size of the present computational investigation ( 240 optimizations $)$ imposed a too heavy burden under the more rigorous approach. The impact of the approximation was estimated by comparing the two approaches for two test cases (see details in the Supporting Information): 
C-PCM optimizations gave slightly lower free energies (ca. $2 \mathrm{kcal} \mathrm{mol}^{-1}$ ) and slightly shorter (ca. $0.03 \AA$ ) hydrogen bonds, whereas the covalent bonds changed by $<0.01 \AA$.

\section{Results}

As is well appreciated, the appropriate description of the reaction energetics for a catalytic reaction must consider solvent effects. ${ }^{66}$ The present study makes use of the C-PCM approach ${ }^{60}$, ${ }^{61}$ in aniline, which is both the substrate and the medium of the catalyzed transformation. When charged species are involved in solvents of low permittivity, ion pairing may also tune the potential energy surface. A recent study of this platinum system (notably reactions that involve compounds $\mathbf{1 , 2}$ and 3 ) has explicitly addressed the effect of the countercation in the calculations of reaction energetics, as well as the adequacy of different approaches for handling the free energy of solvation when placing the gas-phase optimized molecule into the solvent cage. ${ }^{67}$ Indeed, upon going from the gas phase to the solution phase the translational and rotational contributions to the partition function are partially quenched, as well as the PV term which relates energy and enthalpy. No universal agreement exists on the best thermodynamic correction of the computed electronic energy to yield the free energy of solutes in condensed media. The inclusion of the countercation introduced significant ion pairing effects in the order dianion $>>$ monoanion. Relative changes for ligand exchange reactions, however, were smaller, especially when the reaction under consideration did not involve doubly charged species. Both effects of introducing the counterion, on one side, and completely neglecting the gas phase entropy term, on the other side, introduced relative changes of up to a few $\mathrm{kcal} \mathrm{mol}^{-1}$ for the reaction energetics. As a possible result of compensation of errors, the best match with the experimental results was obtained when applying the full gas phase thermodynamic correction $\left(\Delta \mathrm{G}^{\mathrm{CPCM}}=\right.$ $\Delta \mathrm{G}_{\text {gas }}+\Delta \Delta \mathrm{G}_{\text {solv }}$ where $\Delta \mathrm{G}_{\text {gas }}$ is the free energy change of the reaction in the gas phase and $\Delta \mathrm{G}_{\text {solv }}$ is the free energy of solvation for each compound), without the inclusion of the countercation. 
This approach will therefore be applied also to the present investigation. Since the reaction pathway that will be explored involves exclusively singly charged and neutral species, and on the basis of the relatively good agreement found in our previous investigations, ${ }^{49,} 67$ the computed free energies reported in this contribution for intermediates and transition states provide at least an indication of the preferred pathway of the catalytic cycle, although a quantitative estimation of accuracy is not possible.

All computed systems are labelled with Roman numerals. Views of all the optimized geometries are given in the Supporting Information (Figure S1), although the most relevant structures will also be shown within the main text. For complexes corresponding to the isolated compounds (1-6), the numbers correspond; for instance, the $\left[\mathrm{PtBr}_{4}\right]^{2-}$ ion of compound $\mathbf{1}$ is given label $\mathbf{I}$, the $\left[\mathrm{PtBr}_{3}\left(\mathrm{C}_{2} \mathrm{H}_{4}\right)\right]^{-}$ion of compound $\mathbf{2}$ is labelled as II, etc. All geometry optimizations were carried out without any simplification (all atoms were treated quanto-mechanically). The thermal corrections were carried out at the standard $298.15 \mathrm{~K}$ temperature and at $423.15 \mathrm{~K}$ (temperature used for the catalytic runs). ${ }^{24-26}$ As the temperature dependence is generally very small, only the standard values will be discussed while those at $423.15 \mathrm{~K}$ will be shown in parentheses in all figures. A full list of the electronic energies and the thermal and solvation corrections is available as Supporting Information (Table S1). All reported $\Delta \mathrm{G}^{\mathrm{CPCM}}$ values are given relative to $\left[\mathrm{PtBr}_{4}\right]^{2-}, \mathbf{I}$, taking into account the values of all species that are added to or subtracted from the system. Because all species calculated during this study have a smaller negative charge than the reference compound (either -1 or neutral) and because more highly charged species are better solvated than less highly charged ones, all solution relative free energy values are less negative (or more positive) than the corresponding gas phase relative free energy values. We have also calculated the relative energy of compound trans- $\mathrm{PtBr}_{2}\left(\mathrm{PhNH}_{2}\right)_{2}(\mathbf{V I}$ '), which was not considered in the previous contributions. ${ }^{49}$ It was found as more stable than the cis isomer VI by ca. $8 \mathrm{kcal} / \mathrm{mol}$, but still less stable than II by ca. $4 \mathrm{kcal} / \mathrm{mol}$. Thus, II is still predicted as the lowest free energy species in solution and the presumed catalytic resting state. 


\section{(a) Nucleophilic addition of aniline to coordinated olefin}

As stated in the Introduction (Scheme 2), systems II, IV, V, VII and VIII are all likely candidates for the nucleophilic addition step of the olefin activation mechanism of the catalytic cycle. As illustrated in Figure 1 through the example of the LUMO of complex II, the nucleophilic addition to a coordinated olefin could be imagined to occur either intermolecularly via direct addition (anti, pathway 1, or syn, pathway 2) or intramolecularly through preliminary coordination (pathway 3 , leading either to a 4 - or a 5-coordinated intermediate). Pathway 1 is the ubiquitous pathway for nucleophilic addition to coordinated olefins,,${ }^{1}$ but evidence for a $s y n$ attack with preliminary metal coordination through a 5-coordinate intermediate (pathway 3 ) has been presented for the $\mathrm{OH}^{-}$addition to related $\mathrm{Pd}$ systems ${ }^{68-70}$ and evidence for the existence of 5-coordinate $\mathrm{PtCl}_{2}\left(\mathrm{C}_{2} \mathrm{H}_{4}\right)(\text { py })_{2}$ also exists. ${ }^{71}$ Both geometric ${ }^{72,} 73$ and steric factors ${ }^{74}$ in the substrate, as well as the nucleophile nature,${ }^{75}$ have been proposed to steer the pathway one way or the other. The possibility of a direct syn addition (pathway 2) is not systematically considered. $^{1,32} \mathrm{We}$ wished to probe all possible pathways in our case. Note that this step is common to the catalytic cycle of the Wacker process. ${ }^{76}$

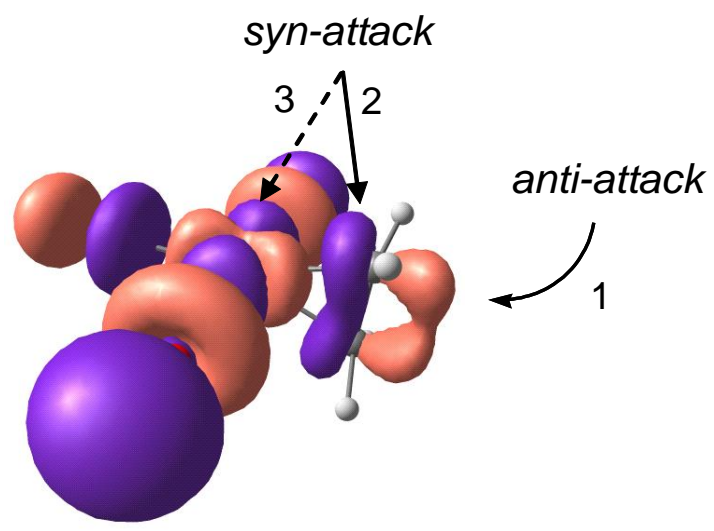


Figure 1. Possible pathways for the nucleophilic attack of the coordinated olefin in II (a) and a view of the $\operatorname{LUMO}\left(\mathrm{A}_{1}, \mathrm{E}=0.0433\right.$ Hartree $)$ for II.

All attempts to optimize the putative 18-electron complexes $\left[\mathrm{PtBr}_{3}\left(\mathrm{C}_{2} \mathrm{H}_{4}\right)\left(\mathrm{PhNH}_{2}\right)\right]^{-}$or trans- $\left[\mathrm{PtBr}_{2}\left(\mathrm{C}_{2} \mathrm{H}_{4}\right)\left(\mathrm{PhNH}_{2}\right)_{2}\right]$ by suitably placing the aniline at bonding distance to the $\mathrm{Pt}$ atom along the $\mathrm{z}$ direction of the square plane of systems II and IV were unsuccessful, always leading

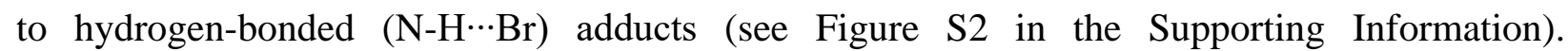
Comparative studies of the direct anti (1) and syn (2) additions were only carried out for systems II and IV through appropriate scans of the C-N distance (Figure S3). For compound V, which already contains aniline within the coordination sphere, an intramolecular syn addition (following pathway 3 of Figure 1) was compared with the intermolecular anti attack (Figure S4). Since the minimized parameter is the gas phase electronic energy, with the entropic and solvation effects varying along the reaction coordinate, a fully optimized transition state structure does not necessarily corresponds to the maximum along the solution free energy curve. Indeed, the highest solution free energy for the intermolecular pathways corresponds to a much longer C$\mathrm{N}$ distances (earlier transition state) relative to the gas phase, because of the relatively good stabilization by solvation of the zwitterionic character that develops along the addition coordinate. For each system, the highest point along the $\Delta \mathrm{G}^{\mathrm{CPCM}}$ curve is lower for the anti attack (values in $\mathrm{kcal} \mathrm{mol}^{-1}$ ): for II, 11.1 (anti) and 19.9 (syn); for IV, 8.1 (anti) and 19.9 (syn); and for $\mathbf{V}, 13.9$ (anti) and 45.5 for the intramolecular syn addition. A related computational study of the nucleophilic attack of gold-coordinated 1,3-dienes by N-based nucleophiles also shows the absence of coordination and a more facile direct anti addition. ${ }^{31}$ The addition coordinate for systems VII and VIII was therefore investigated only for the anti attack (Figure S5).

The results of the anti nucleophilic additions are summarized graphically in Figure 2. The relative barrier heights correlate with the $\mathrm{C}-\mathrm{C}$ bond lengths in the starting olefin complex ${ }^{49}$ (greater barriers are associated to longer $\mathrm{C}-\mathrm{C}$ bonds), in agreement with the notion that a longer 
$\mathrm{C}-\mathrm{C}$ bond reflects a greater degree of $\pi$ back-bonding and thus higher electron density on the $\mathrm{C}_{2} \mathrm{H}_{4}$ ligand, disfavoring the attack. Upon considering the different relative stability of the starting complexes, the nucleophilic addition occurs more easily in the order II $<$ V $<$ IV $<$ VIII $<$ VII.

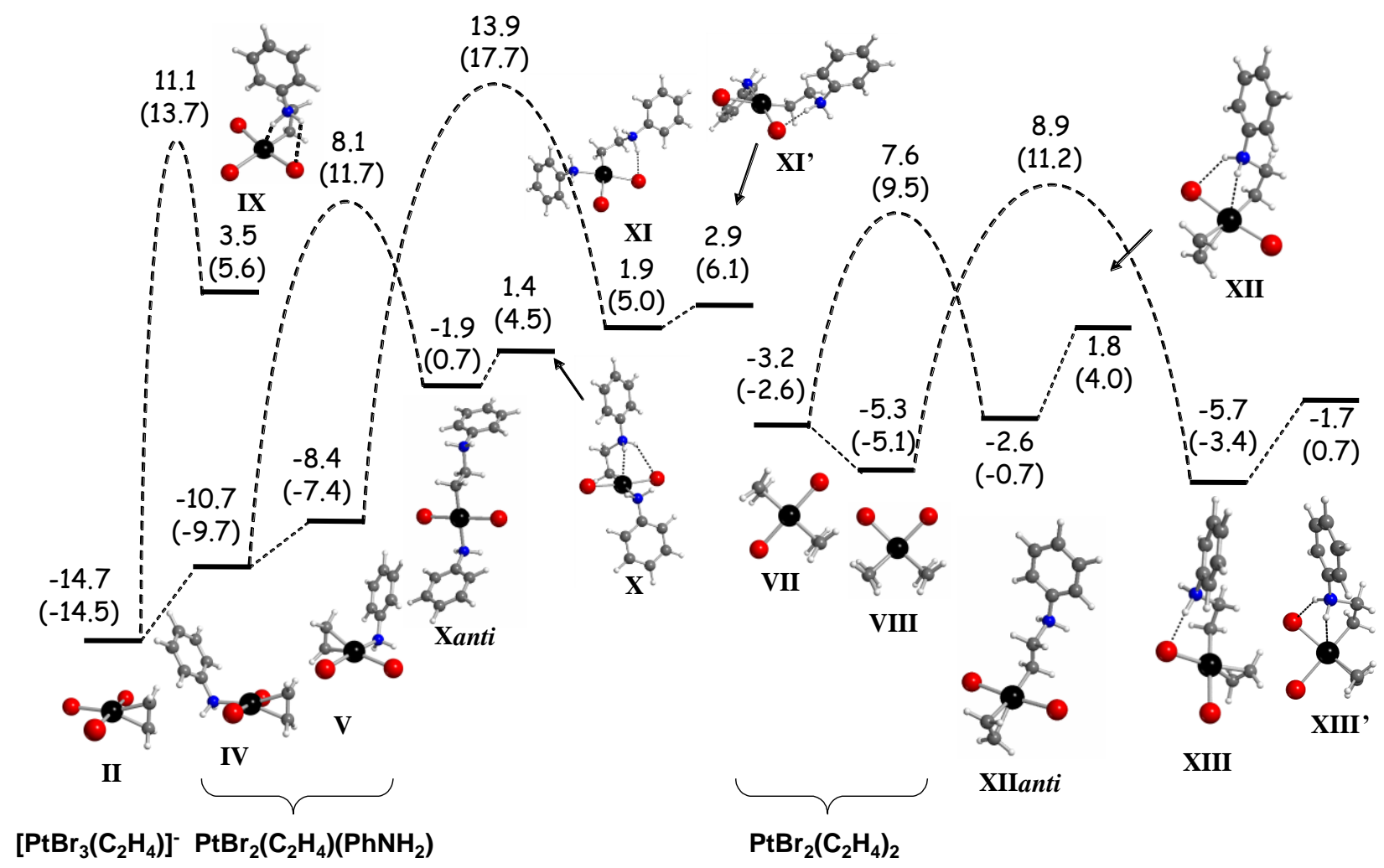

Figure 2. $\Delta \mathrm{G}^{\mathrm{CPCM}}$ in $\mathrm{kcal} \mathrm{mol}^{-1}$ at $298.15 \mathrm{~K}$ (and at $423.15 \mathrm{~K}$ in parentheses) for the reagents, products and highest points along the aniline nucleophilic addition to coordinated ethylene in systems II, IV, V, VII and VIII. Optimized geometries are also shown for the reagents and products.

Full geometry optimization beyond the addition barrier led in each case to a stable zwitterionic intermediate, shown in Figure 2. These systems show an interesting variety of intramolecular $\mathrm{H}$-bonding patterns, where the ammonium protons interact mainly with the $\mathrm{Pt}$ atom, or a $\mathrm{Br}$ atom, or both, or none. In a few cases, different minima could be optimized for the same molecule. More details are given in the supporting information (Scheme S1 and relevant structural parameters in Table S2). It is relevant to mention here that the only crystallographically characterized complex having this stoichiometry, trans- 
$\mathrm{PtCl}_{2}\left(\mathrm{Et}_{2} \mathrm{NH}\right)\left(\mathrm{CH}_{2} \mathrm{CH}_{2} \mathrm{NHEt}_{2}\right),{ }^{77}$ exhibits an intramolecular $\mathrm{N}-\mathrm{H} \cdots \mathrm{Cl}$ interaction $(\mathrm{N} \cdots \mathrm{Cl}=3.20$ $\AA$ A $\mathrm{H}$ atoms were not directly located).

It may be argued that the gas phase optimized structures are not relevant for the behavior in solution, because the ammonium N-H protons could establish stronger H-bonds with aniline molecules in the medium. To shine more light on this problem we have performed additional calculations taking the particular case of complex XIII. Starting from the optimized isomer XIII', addition of an aniline molecule next to each of the two N-H protons led to systems XIII $\cdot \mathrm{PhNH}_{2}$ (a and b, see Figure 3). These complexes are ca. $7 \mathrm{kcal} / \mathrm{mol}$ higher than XIII' on the $\Delta \mathrm{G}^{\mathrm{CPCM}}$ scale. However, they are 12.2 and $10.8 \mathrm{kcal} / \mathrm{mol}$ more stable, respectively, on the $\Delta \mathrm{E}_{\text {gas }}$ scale. Full entropy neglect in the $\Delta \mathrm{E}^{\mathrm{CPCM}}$ scale $\left(\Delta \mathrm{E}_{\text {gas }}+\Delta \mathrm{G}_{\text {solv }}\right)$ also gives greater stability for the aniline adducts (by 3.9 and $2.4 \mathrm{kcal} / \mathrm{mol}$, respectively), but this approximation is also unjustified. As noted above, the correct handling of the entropy for accurate calculation of equilibrium positions is one of the outstanding challenges for computational chemistry.

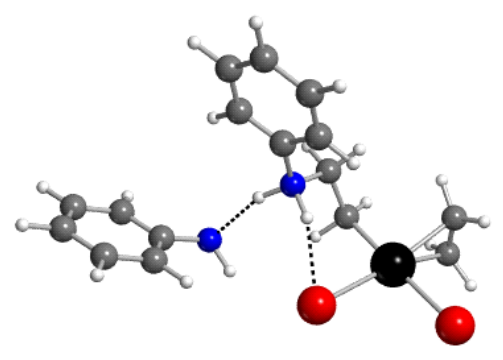

$4.6(9.3)$

$[-2.4(0.6)]$

XIII $\cdot \mathrm{PhNH}_{2}(\mathbf{a})$

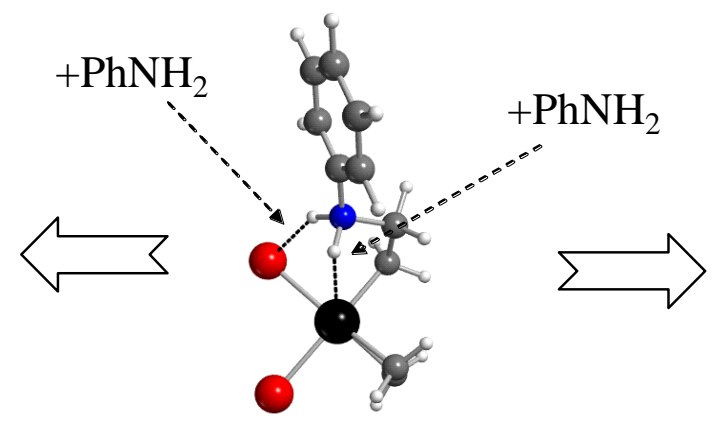

$-1.7(0.7)$

XIII'

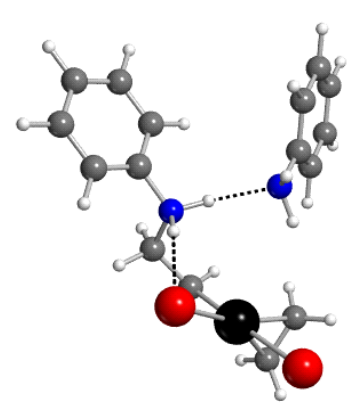

$5.6(10.3)$

$[-1.5(1.6)]$

XIII $\cdot \mathrm{PhNH}_{2}(\mathbf{b})$

Figure 3. Optimized geometries and $\Delta \mathrm{G}^{\mathrm{CPCM}}$ in $\mathrm{kcal} \mathrm{mol}^{-1}$ at $298.15 \mathrm{~K}$ (and at $423.15 \mathrm{~K}$ in parentheses) for systems $\mathbf{X I I I} \cdot \mathrm{PhNH}_{2}(\mathbf{a}$ and $\mathbf{b})$. The values in brackets correspond to $\Delta \mathrm{G}^{\mathrm{CPCM}}{ }_{\text {cor }}$ (see text).

Note that the calculation of the relative energy value from the reference system $\mathbf{I}$, as outlined in equation 1, involves a different number of molecules on each side. Solvation entropy could play a major role in this equilibrium because of the different number of translational and 
rotational degrees of freedom. In an attempt to better handle the entropy problem we reduced the number of independent species on the left hand side of the equation by considering the H-bonded aniline $\cdots$ aniline dimer (equation 2). The resulting free energy change, called $\Delta \mathrm{G}^{\mathrm{CPCM}}{ }_{c o r}$, predicts a greater stability for $\mathbf{X I I I} \cdot \mathrm{PhNH}_{2}$ (a) relative to $\mathbf{X I I I}$ ' by only $0.7 \mathrm{kcal} \mathrm{mol}^{-1}$, whereas XIII $\cdot \mathrm{PhNH}_{2}$ (b) is destabilized by $0.2 \mathrm{kcal} / \mathrm{mol}$. In conclusion, when H-bonding with solvent molecules is taken into account the energetic balance does not seem strongly in favor of intermolecular $\mathrm{H}$-bonding. Note also that the solvent adducts maintain the stronger $\mathrm{Br} \cdots \mathrm{H}$ interaction originally present in XIII', whereas the weaker Pt $\cdots \mathrm{H}$ interaction is lost. Thus the structure and the stability in solution appear to be affected by the interactions with the solvent molecules.

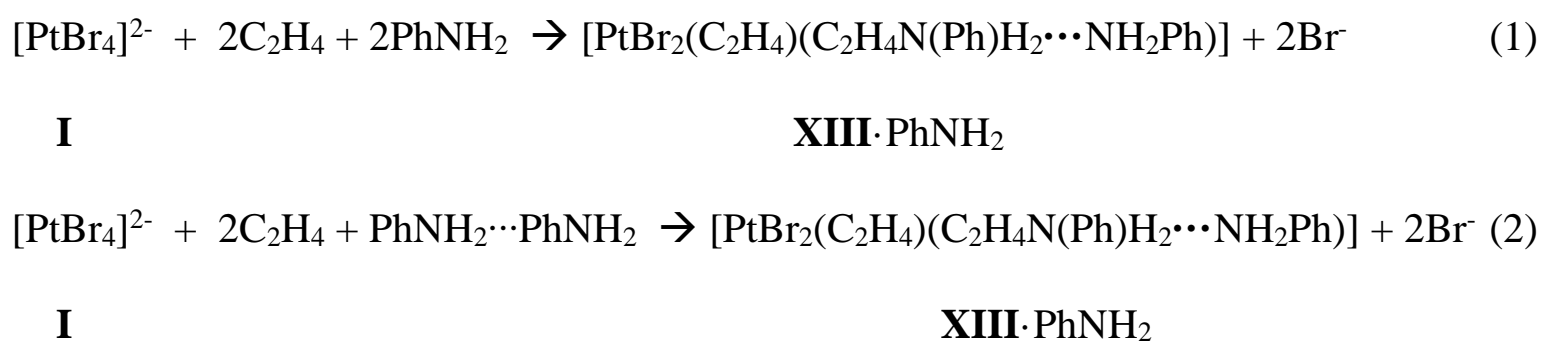

\section{(b) N-H activation}

The aniline N-H oxidative addition to anyone of complexes I-VIII could constitute the initial step of a catalytic cycle operating through the amine activation mechanism. It is mentioned that oxidative addition of unactivated $\mathrm{N}-\mathrm{H}$ bonds to $\mathrm{Pt}^{0} \mathrm{~L}_{2}$ is thermodynamically unfavorable ${ }^{78}$ and hence it may be expected as even less favorable for a $\mathrm{Pt}^{\mathrm{II}}$ system, but computational studies of the amine activation pathway on $\mathrm{Pt}^{\mathrm{II}}$ complexes do not seem to be available. Hence, we have investigated the energetics of this process. This process was only investigated for complexes I and II, leading to systems XIV-XIX. 
Complex cis-[ $\left[\mathrm{PtBr}_{4} \mathrm{H}(\mathrm{NHPh})\right]^{2-}, \mathbf{X I V}$, results from $\mathrm{N}-\mathrm{H}$ oxidative addition to I. No isomeric variant is possible except for the trans structure, which is not accessible by direct oxidative addition. Oxidative addition to II affords mer-[ $\left.\mathrm{PtBr}_{3}\left(\mathrm{C}_{2} \mathrm{H}_{4}\right)(\mathrm{H})(\mathrm{NHPh})\right]^{-}$, for which three orientations are possible: $\mathrm{N}-\mathrm{H}$ addition across the Br-Pt- $\left(\mathrm{C}_{2} \mathrm{H}_{4}\right)$ axis of II with the ligand ending up trans to $\mathrm{C}_{2} \mathrm{H}_{4}$ being either $\mathrm{NHPh}(\mathbf{X V})$ or $\mathrm{H}\left(\mathbf{X V}^{\prime}\right)$, and $\mathrm{N}-\mathrm{H}$ oxidative addition across the Br-Pt-Br axis of II, yielding isomer XVI. All these isomers are approximately isoenergic and highly disfavored, with a much higher free energy than the highest point of the energy profile for the olefin activation pathway (vide infra).

Loss of a bromide ligand from complex XIV may occur to afford a 5-coordinate $\left[\mathrm{PtBr}_{3} \mathrm{H}(\mathrm{NHPh})\right]^{-}$complex, XVII, which may also be obtained by $\mathrm{N}-\mathrm{H}$ oxidative addition to the 14-e complex $\left[\mathrm{PtBr}_{3}\right]^{-}$. The relative free energy of XVII is lower $\left(27.8 \mathrm{kcal} \mathrm{mol}^{-1}\right)$ than that of XIV, but still too high to make this pathway competitive (vide infra). Dissociation of a bromide ligand from the three isomeric complexes $\mathbf{X V}, \mathbf{X V}$, and $\mathbf{X V I}$ yields three $\left[\mathrm{PtBr}_{2}\left(\mathrm{C}_{2} \mathrm{H}_{4}\right) \mathrm{H}(\mathrm{NHPh})\right]$ geometric isomers, XVIII-XIX, which are again highly energetic. In conclusion, all these calculated models lie too high in energy, showing that the aniline $\mathrm{N}-\mathrm{H}$ oxidative addition to $\mathrm{Pt}^{\mathrm{II}}$ is thermodynamically unfavorable and casting serious doubts on the likelihood of an aniline activation mechanism for this catalytic system.

\section{(c) Further transformations of the zwitterionic complexes}

As mentioned in the introduction, $\mathrm{Pt}^{\mathrm{II}}$ zwitterionic complexes resulting from the nucleophilic addition of basic amines to coordinated olefins have previously been described. ${ }^{77,79-}$

85 These complexes appear to be stable toward the $\beta-\mathrm{H}$ elimination process, ${ }^{30,81}$ whereas analogous $\mathrm{Pd}^{\mathrm{II}}$ systems may undergo this transformation leading to oxidative amination products instead of hydroamination. ${ }^{1,3,30}$ The intramolecular $\mathrm{N}-\mathrm{H} \cdots \mathrm{X}(\mathrm{X}=\mathrm{Pt}$ or Br) hydrogen bonding observed in the optimized geometries of systems IX-XIII could set the stage for an 
intramolecular proton transfer (see Scheme 3) that may constitute the first step of the pathway leading from the zwitterionic intermediate to product release. The $\mathrm{N}-\mathrm{H} \cdots \mathrm{Pt}$ bond (A) could generate a $\mathrm{Pt}^{\mathrm{IV}}$ hydride complex by proton transfer to the $\mathrm{Pt}$ atom $(\mathbf{B})$, whereas the $\mathrm{N}-\mathrm{H} \cdots \mathrm{Br}$ bond (C) could promote $\mathrm{HBr}$ elimination as $\mathrm{PhNH}_{2}{ }^{+} \mathrm{Br}^{-}$, leading to chelation of the $\mathrm{CH}_{2} \mathrm{CH}_{2} \mathrm{NHPh}$ ligand to generate a platinaazacyclobutane derivative (D), although the latter could also occur in two steps, promoted by an external base. Examples of this process were reported for derivatives of type $\operatorname{cis}-\mathrm{PtCl}_{2}\left(\mathrm{C}_{2} \mathrm{H}_{4}\right)(\mathrm{Y})\left(\mathrm{Y}=\mathrm{PR}_{3}\right.$, py, $\mathrm{NH}_{3}$, am, DMSO), ${ }^{84,86-88}$ $\operatorname{PtCl}(\mathrm{PyPyr})\left(\mathrm{C}_{2} \mathrm{H}_{4}\right)^{89}$ and $[\mathrm{PtCl}(\text { alkene })(\text { tmeda })]^{+} \cdot{ }^{90}$ Chelation of the deprotonated alkyl ligand in $\mathbf{B}$ would also afford a platinacyclic derivative $\mathbf{E}$, though this is a $\mathrm{Pt}^{\mathrm{IV}}$ derivative, which is related to $\mathbf{D}$ by a formal oxidative addition of $\mathrm{HBr}$. There is at least one literature precedent of the interconversion between a $\mathrm{N}-\mathrm{H} \cdots \mathrm{Pt}$ zwitterionic complex of type $\mathbf{A}, \operatorname{PtBr}\left(\kappa^{2}-C, N-\right.$ $\left.\mathrm{C}_{6} \mathrm{H}_{4} \mathrm{CH}_{2} \mathrm{NMe}_{2}-2\right)\left(\kappa^{1}-C-\mathrm{C}_{6} \mathrm{H}_{4} \mathrm{CH}_{2} \mathrm{NHMe}_{2}-2\right)$, and a 6-coordinated $\mathrm{Pt}^{\mathrm{IV}}$ hydride complex of type E, $\operatorname{Pt}(\mathrm{H}) \mathrm{Br}\left(\kappa^{2}-C, N-\mathrm{C}_{6} \mathrm{H}_{4} \mathrm{CH}_{2} \mathrm{NMe}_{2}-2\right)_{2} .{ }^{91}$ Systems $\mathbf{B}$ and $\mathbf{D}$ may also be generated by the alternative intermolecular deprotonation of $\mathbf{A}$ or $\mathbf{C}$ by aniline to generate $\mathbf{F}$ followed by reprotonation or $\mathrm{Br}^{-}$displacement. Both derivatives of type $\mathbf{D}^{28,89,92-94}$ and $\mathbf{F}^{21,89,95}$ have been proposed in the literature as catalytic intermediates for the hydroamination reaction, but their possible role in the olefin activation mechanism has not been firmly established.

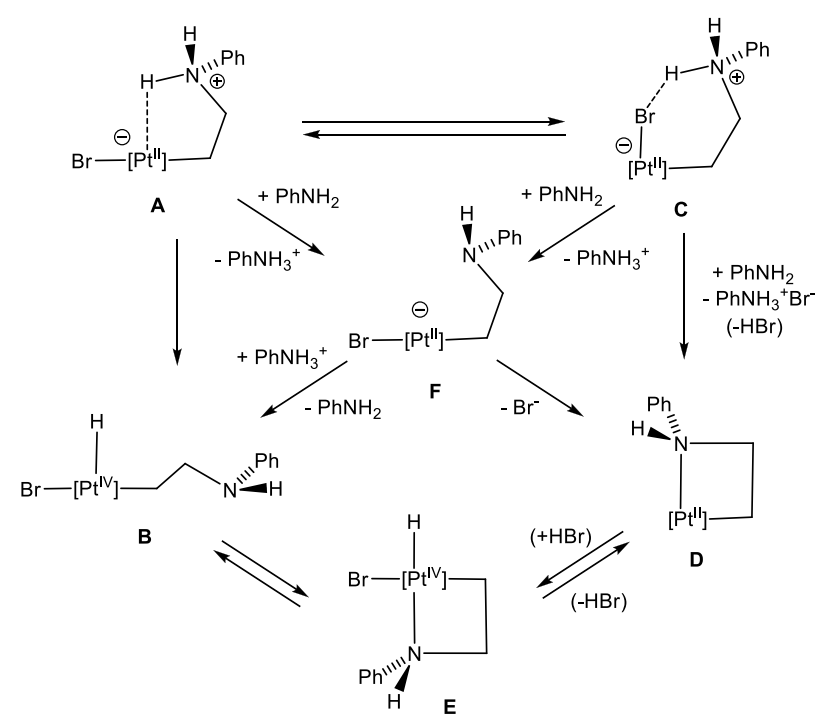


Scheme 3. Different geometrical arrangement found for the $\left[\mathrm{Pt}-\mathrm{CH}_{2} \mathrm{CH}_{2} \mathrm{NHPh}\right]$ moiety.

The ultimate liberation of the hydroamination product can then be envisaged through a C$\mathrm{H}$ reductive elimination from $\mathbf{B}$ or $\mathbf{E}$, or by direct protonolysis of the $\mathrm{Pt}-\mathrm{C}$ bond in the dangling alkyl derivatives (e.g. $\mathbf{A} / \mathbf{C}, \mathbf{B}$ or $\mathbf{F}$ ) or metallacycles (e.g. D or $\mathbf{E})$. However, a direct intramolecular proton transfer from the ammonium function in $\mathbf{A}$ or $\mathbf{C}$ to the carbon atom, possibly assisted by an additional external aniline molecule in a proton shuttle mechanism, may also be operational, as predicted by the model investigation of the $\mathrm{NH}_{3}$ addition to $\mathrm{C}_{2} \mathrm{H}_{4}$ catalyzed by $\left[\mathrm{PtCl}\left(\mathrm{PH}_{3}\right)_{2}\right]^{+} .32$ The rest of this section will explore all these possibilities.

c1. Intramolecular proton transfer to Pt: formation of $\mathrm{Pt}^{I V}-\mathrm{H}$ intermediates. Because of the Pt $\cdots \mathrm{H}$ interaction, systems $\mathbf{I X}$ and $\mathbf{X}$ seem perfectly set up for transferring a proton from $\mathrm{N}$ to $\mathrm{Pt}$, with formal oxidation to $\mathrm{Pt}^{\mathrm{IV}}$, but system XI, XII and XIII' must also be considered. Indeed, moving the H-bonded hydrogen atom from $\mathrm{N}$ to $\mathrm{Pt}$ in $\mathbf{I X}$ yielded $\mathbf{X X}$ as a stable minimum with a square pyramidal geometry where a new H-bond has developed between the residual N-H bond of the axial $\mathrm{CH}_{2} \mathrm{CH}_{2} \mathrm{NHPh}$ ligand and an equatorial $\mathrm{Br}$ ligand $(\mathrm{H} \cdots \mathrm{Br}=2.59 \AA)$, see Figure 4. The Br ligand that was originally trans to the alkyl chain in IX has moved trans to the $\mathrm{H}$ ligand in $\mathbf{X X}$. The $\Delta \mathrm{G}^{\mathrm{CPCM}}$ value of this structure is $9.5 \mathrm{kcal} \mathrm{mol}^{-1}$ vs. $3.5 \mathrm{kcal} \mathrm{mol}^{-1}$ for the precursor IX. This is the most stable 5-coordinate $\mathrm{Pt}^{\mathrm{IV}}-\mathrm{H}$ complex found in our studies. Starting from $\mathbf{X}$ and XI, the higher energy 16-electron $\mathrm{Pt}^{\mathrm{IV}}-\mathrm{H}$ complexes XXI, XXII and XXII' where obtained as detailed in the Supporting Information, whereas we were not able to obtain any new $\mathrm{Pt}^{\mathrm{IV}}-\mathrm{H}$ local minimum starting from the stoichiometries of XII and XIII'. Note that, among all the zwitterionic complexes, IX displays the most electron-rich Pt atom and is thus the most susceptible one to transfer a proton to the metal center and generate a $\mathrm{Pt}^{\mathrm{IV}}$ hydride complex, as previously predicted. ${ }^{26}$ 

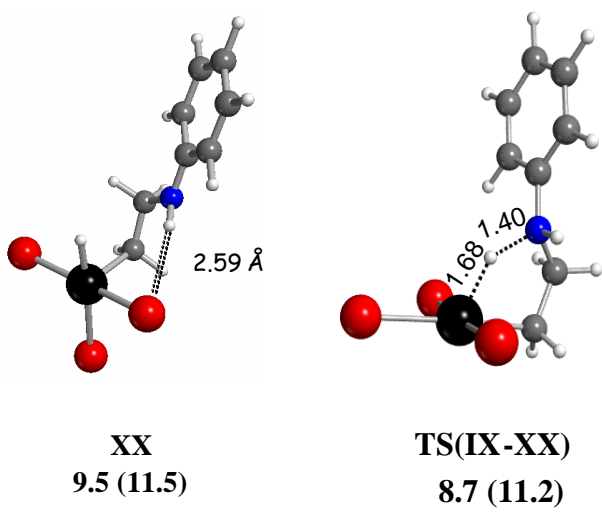

Figure 4. Optimized geometries and $\Delta \mathrm{G}^{\mathrm{CPCM}}$ in $\mathrm{kcal} \mathrm{mol}^{-1}$ at $298.15 \mathrm{~K}$ (and at $423.15 \mathrm{~K}$ in parentheses) for the lowest energy 5-coordinate Pt(IV) hydride complex $\mathbf{X X}$ and for the transition state $\mathbf{T S}(\mathbf{I X}-\mathbf{X X})$ leading to it.

Optimization of the transition state for this process gave geometry TS(IX-XX), Figure 4, where the $\mathrm{H}$ atom is ca. midway between the two local minima and its Mulliken charge $(0.28)$ is also midway between the more proton-like value of 0.44 in IX and the more hydride-like value of 0.11 in $\mathbf{X X}$. The structure shows only one imaginary frequency $\left(397 \mathrm{im}^{-1}\right)$ corresponding to the $\mathrm{H}$ atom movement from $\mathrm{N}$ to Pt. On the energy scale, TS(IX-XX) is barely higher (ca. $1 \mathrm{kcal}$ $\mathrm{mol}^{-1}$ ) than $\mathbf{I X}$, which is less stable than $\mathbf{X X}$, whereas $\Delta \mathrm{G}^{\mathrm{CPCM}}$ increases in the order $\mathbf{I X}(3.5)<$ TS(IX-XX) (8.7) < XX (9.5), suggesting that the real transition state geometry is closer to that of $\mathbf{X X}$ and that the rearrangement is very facile.

Since systems XX-XXII are formally 5-coordinate $\mathrm{Pt}^{\mathrm{IV}}$ complexes, a reasonable question is whether they may be stabilized by addition of one of the several available ligands $\left(\mathrm{Br}^{-}, \mathrm{PhNH}_{2}\right.$, $\mathrm{C}_{2} \mathrm{H}_{4}$ ) or by chelation of the aminoalkyl ligand to yield 18-electron octahedral products ( $\mathbf{E}$ in Scheme 3). This question was probed for the most stabilized of the above described hydride systems, namely $\mathbf{X X}$. Three systems were constructed by adding ligands $\mathrm{Br}^{-}, \mathrm{PhNH}_{2}$ and $\mathrm{C}_{2} \mathrm{H}_{4}$ to the empty position trans to the $\mathrm{CH}_{2} \mathrm{CH}_{2} \mathrm{NHPh}$ to yield systems XXIII, XXIV, XV, respectively. The possible generation of platina(IV)azacyclobutane derivates from XX-XXII will be analyzed later in a separate section. All geometries of XXIII-XXV optimized smoothly, see Figure 5. An 
alternative orientation for the ethylene ligand (XXIV': parallel to the Br-Pt-Br axis rather than to the $\mathrm{H}-\mathrm{Pt}-\mathrm{Br}$ axis) resulted in a higher $\Delta \mathrm{G}^{\mathrm{CPCM}}$ value. Two isomeric possibilities for the aniline addition product, $\mathbf{X X V}$ ' and $\mathbf{X X V}$ ", were also optimized, the most stable arrangement $\mathbf{X X V}$, featuring a trans disposition of the aniline and hydride ligands. All these 6-coordinate adducts are in fact more stable than the 5-coordinate precursor on the energy scale, but most are higher on the $\Delta \mathrm{G}^{\mathrm{CPCM}}$ scale. Only $\mathbf{X X V}$, is slightly stabilized. This suggests that the coordinatively unsaturated $\mathrm{Pt}^{\mathrm{IV}}-\mathrm{H}$ complex $\mathbf{X X}$ is a viable catalytic intermediate.

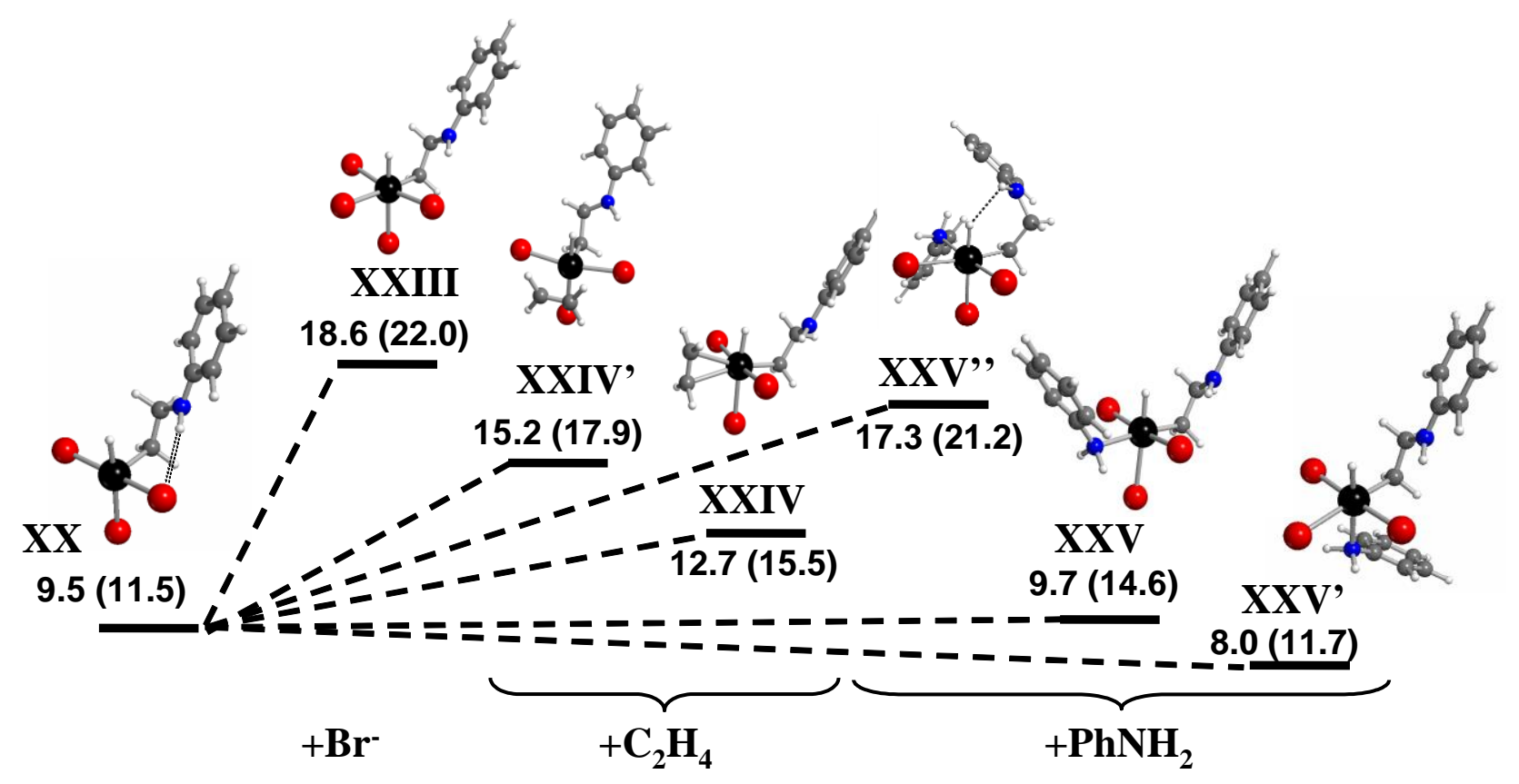

Figure 5. Optimized geometries and $\Delta \mathrm{G}^{\mathrm{CPCM}}$ in $\mathrm{kcal} \mathrm{mol}^{-1}$ at $298.15 \mathrm{~K}$ (and at $423.15 \mathrm{~K}$ in parentheses) for 6-coordinate $\mathrm{Pt}^{\mathrm{IV}}$ hydride complexes.

c2. Intramolecular proton transfer to Br: formation of $\mathrm{Pt}^{I I} \sigma-\mathrm{HBr}$ intermediates. Although it is generally proposed that platina(II)azacyclobutane derivatives form by intermolecular N-H deprotonation of zwitterionic complexes (pathway $\mathbf{A}($ or $\mathbf{C}) \rightarrow \mathbf{F} \rightarrow \mathbf{D}$ in Scheme 3), ${ }^{84,87,89,90,96-}$ 98 we wished to also explore the energetics of a possible intramolecular proton transfer to a $\mathrm{Br}$ atom as a preliminary step for the $\mathrm{HBr}$ elimination process. We have considered this pathway starting only from $\mathbf{X I} / \mathbf{X I}$ ' and $\mathbf{X I I I} / \mathbf{X I I I}$ ', which feature the strongest $\mathrm{N}-\mathrm{H} \cdots \mathrm{Br}$ interactions. Attempts to move the proton from $\mathrm{N}-\mathrm{H} \cdots \mathrm{Br}$ to $\mathrm{N} \cdots \mathrm{H}-\mathrm{Br}$ did not lead to a stable minimum, 
converging back to the zwitterionic intermediate. Stable minima were found only when the $\mathrm{H}$ atom was placed on the opposite side of the Br ligand, facing the second Br ligands, XXVI from XIII (H-Br: $1.46 \AA ;$ Pt $\cdots H=2.87 \AA ; \mathrm{Pt} \cdots \mathrm{Br}=2.96 \AA)$ and XXVII from XI or XI' (H-Br: 1.50 $\AA ; \mathrm{Pt}^{\cdots} \cdot \mathrm{H}=2.70 \AA ; \mathrm{Pt} \cdots \mathrm{Br}=2.91 \AA$ ). Both structures are characterized by an additional intramolecular H-bond, Br $\cdots \mathrm{H}-\mathrm{N}$ for XXVI and $\mathrm{N} \cdots \mathrm{H}-\mathrm{N}$ for XXVII. The high energy of these species compared to other pathways (vide infra) make them unlikely candidates as catalytic intermediates.

c3. Deprotonation of the zwitterionic complexes. The $-\mathrm{CH}_{2}-\mathrm{CH}_{2}-\mathrm{N}^{(+)} \mathrm{H}_{2} \mathrm{Ph}$ ligand in the zwitterionic systems IX-XIII (Figure 2) could also undergo intermolecular deprotonation by excess aniline (pathway $\mathbf{A}$ (or $\mathbf{C}$ ) $\rightarrow \mathbf{F}$ in Scheme 3) to yield derivative containing the 2aminoethyl moiety, Pt- $\mathrm{CH}_{2} \mathrm{CH}_{2} \mathrm{NHPh} .{ }^{99}$ Proton removal from $\mathbf{I X}$ led to $\left[\mathrm{PtBr}_{3}\left(\mathrm{CH}_{2} \mathrm{CH}_{2} \mathrm{NHPh}\right)\right]^{2-}$ , XXVIII, the trans- and cis- aniline systems X ( or Xanti) and XI (or XI') led to trans- and cis$\left[\mathrm{PtBr}_{2}\left(\mathrm{PhNH}_{2}\right)\left(\mathrm{CH}_{2} \mathrm{CH}_{2} \mathrm{NHPh}\right)\right]^{-}, \mathbf{X X I X}$ and $\mathbf{X X X}$, and finally the the trans- and cis- ethylene systems XII (or XIIanti) and XIII (or XIII') led to trans- and cis$\left[\mathrm{PtBr}_{2}\left(\mathrm{C}_{2} \mathrm{H}_{4}\right)\left(\mathrm{CH}_{2} \mathrm{CH}_{2} \mathrm{NHPh}\right)\right]^{-}, \mathbf{X X X I}$ and $\mathbf{X X X I I}$. The most stable derivative is XXXII, shown in Figure 6. The dianionic derivative XXVIII has a very high energy (29.8 $\left.\mathrm{kcal} \mathrm{mol}^{-1}\right)$, whereas the others (XXIX-XXXI) have intermediate energies (18-22 $\left.\mathrm{kcal} \mathrm{mol}^{-1}\right)$. A comparison between the energies of the $\sigma-(\mathrm{HBr})$ derivatives and the $\mathrm{Pt}-\mathrm{CH}_{2} \mathrm{CH}_{2} \mathrm{NHPh}$ complexes suggests that the direct intermolecular deprotonation of $\mathrm{Pt}-\mathrm{CH}_{2} \mathrm{CH}_{2} \mathrm{~N}^{(+)} \mathrm{H}_{2} \mathrm{Ph}$ by aniline is more favourable than transfer to the bromide ligand, though still less favourable than transfer to platinum. 


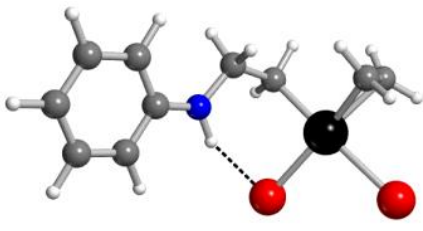

XXXII

$12.6(15.4)$

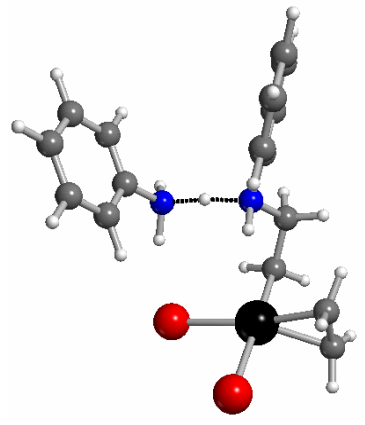

TS(XIII-XXXII)

8.1 (13.7)

[1.0 (5.1)]

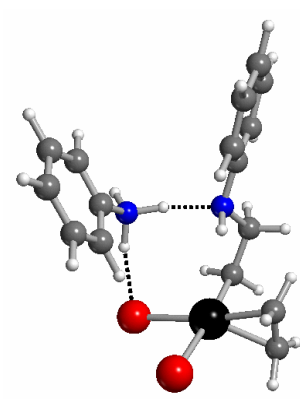

XXXII.PhNH ${ }_{3}^{+}$

$11.2(15.8)$

[4.2 (7.1)]

Figure 6. Optimized geometries and relative $\Delta \mathrm{G}^{\mathrm{CPCM}}$ in $\mathrm{kcal} \mathrm{mol}^{-1}$ at $298.15 \mathrm{~K}$ (and at $423.15 \mathrm{~K}$ in parentheses) for the lowest energy aminoethyl complex, XXXII, and for the stationary points along the deprotonation of XIII by aniline. The values in brackets correspond to $\Delta \mathrm{G}^{\mathrm{CPCM}}$ cor (see text).

The deprotonation pathway was analyzed more in detail only for the most stable complex. This involves the initial formation of a hydrogen-bonded adduct between XIII and aniline to give $\mathbf{X I I I} \cdot \mathrm{PhNH}_{2}$ (A) (see above, Figure 3), then proton transfer via TS(XIII-XXXII) leading to an H-bonded adduct between XXXII and anilinium, XXXII $\cdot \mathrm{PhNH}_{3}{ }^{+}$(see Figure 6). Like for the above described TS(IX-XX), the transition state TS(XIII-XXXII) is higher in energy with respect to both reactant and product on the energy scale, but actually lower than the final product on the $\Delta \mathrm{G}^{\mathrm{CPCM}}$ scale. On going to the $\Delta \mathrm{G}^{\mathrm{CPCM}}$ cor scale (see equations 1 and 2), the situation does not change, TS(XIII-XXXII) remaining lower than XXXII $\cdot \mathrm{PhNH}_{3}{ }^{+}$(Figure 6). Note that, although the formation of XIII. $\mathrm{PhNH}_{2}(\mathbf{A})$ from the two free components costs a great deal on the $\Delta \mathrm{G}^{\mathrm{CPCM}}$ scale, the formation of $\mathbf{X X X I I} \cdot \mathrm{PhNH}_{3}{ }^{+}$from $\mathbf{X X X I I}$ and $\mathrm{PhNH}_{3}{ }^{+}$actually corresponds to a stabilization. This is probably because the weak $\mathrm{N}-\mathrm{H} \cdots \mathrm{Br}$ interaction in XXXII (the free amine is not a strong acid) is replaced by much stronger $\mathrm{N}-\mathrm{H} \cdots \mathrm{Br}$ and $\mathrm{N}-\mathrm{H} \cdots \mathrm{N}$ interactions (the anilinium ion is a much stronger acid). 
c4. Formation of chelated aminoalkyl Pt complexes. There are two possible types of platinacycles. The first type is 4-coordinate platina(II)cycles that can be generated by coordination of the dangling amine function in the deprotonated systems (XXVIII-XXXII) with replacement of a bromide ligand $(\mathbf{F} \rightarrow \mathbf{D}$ in Scheme 3). The second type is 18-electron platina(IV)cycles that can be obtained by chelation of the dangling aminoalkyl ligand in the 16electron $\mathrm{Pt}^{\mathrm{IV}}-\mathrm{H}$ complexes (XX-XXII), corresponding to process $\mathbf{B} \rightarrow \mathbf{E}$ in Scheme 3. The latter can also be obtained by protonation of the platina(II)cyclic complexes $\mathbf{D}$ followed by bromide addition (formal $\mathrm{HBr}$ oxidative addition), $\mathbf{D} \rightarrow \mathbf{E}$ in Scheme 3.

A detailed analysis of these processed is described in the Supporting Information. In summary, bromide displacement from the deprotonated systems XXVIII-XXXII yields the platina(II)cyclic derivatives XXXIII-XXXV with moderately high energy (14.9-22.4 kcal mol-1). The most stable amongst these $\mathrm{Pt}^{\mathrm{II}}$ metallacyclic complexes, $\mathbf{X X X V}$ ', has $\Delta \mathrm{G}^{\mathrm{CPCM}}$ of $14.9 \mathrm{kcal}$ mol $^{-1}$, just a bit higher than that of its precursor XXXII. The relatively low energy of these complexes allows them to be considered for the moment as potential catalytic intermediates. Note that the thermodynamics of this process should be favoured by stronger bases, rationalizing well the formation of the stable platinacyclic derivatives mentioned above.

Concerning the formation of platina(IV)cycles, chelation of the dangling aminoalkyl function $-\mathrm{CH}_{2} \mathrm{CH}_{2} \mathrm{NHPh}$ in $\mathbf{X X}$ leads to the anionic complexes $\left[\operatorname{PtHBr}_{3}\left(\kappa^{2}: C, N-\right.\right.$ $\mathrm{CH}_{2} \mathrm{CH}_{2} \mathrm{NHPh}$ )] - $^{-} \mathbf{X X X V I - X X X V I I}$, four isomers), whereas the same process starting from XXI and XXII (or XXII') leads to the neutral complexes $\left[\mathrm{PtHBr}_{2}\left(\mathrm{PhNH}_{2}\right)\left(\kappa^{2}: C, N-\mathrm{CH}_{2} \mathrm{CH}_{2} \mathrm{NHPh}\right)\right]$ (XXXVIII-XLIV, 12 isomers). The energy of these systems is relatively low on the $\Delta \mathrm{G}^{\mathrm{CPCM}}$ scale, unless $\mathrm{H}$ and the two most strongly trans directing ligands $\mathrm{H}$ and alkyl are unfavorably located trans to each other (i.e. XXXVII, XXXIX, XLI and XLI'). The thermodynamic balance is favorable for formation of these complexes both with respect to the corresponding systems of type $\mathbf{B}$ and $\mathbf{D}$ in Scheme 3, justifying their consideration as potential catalytic intermediates. The lowest $\Delta \mathrm{G}^{\mathrm{CPCM}}$ derivatives are XXXVI for the anionic system $\left(9.4 \mathrm{kcal} \mathrm{mol}^{-1}\right)$ and XLIII for the 
neutral systems $\left(11.0 \mathrm{kcal} \mathrm{mol}^{-1}\right)$. Their geometry is shown in Figure 7. Additional systems may also be derived by formal $\mathrm{HBr}$ oxidative addition to the ethylene-dibromo isomers $\mathbf{X X X V}$ and XXXV' (corresponding $\mathrm{Pt}^{\mathrm{IV}}-\mathrm{H}$ aminoalkyl complexes could not be optimized for this stoichiometry, vide supra). The nearly isoenergetic diastereomeric pairs $\mathbf{X L V} / \mathbf{X L V}$, and XLVI/XLVI' were generated in this fashion. These are less stabilized (17-19 $\left.\mathrm{kcal} \mathrm{mol}^{-1}\right)$ relative to the corresponding $\mathrm{Pt}^{\mathrm{II}}$ platinacyclic complexes than the other platina(IV)cyclic complexes, since they contain the $\pi$-acceptor ligand $\mathrm{C}_{2} \mathrm{H}_{4}$, which is more compatible with $\mathrm{Pt}^{\mathrm{II}}$ whereas $\mathrm{Pt}^{\mathrm{IV}}$ prefers harder donor ligands.

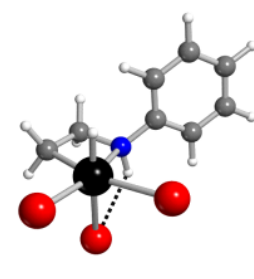

XXXVI

9.4 (11.6)

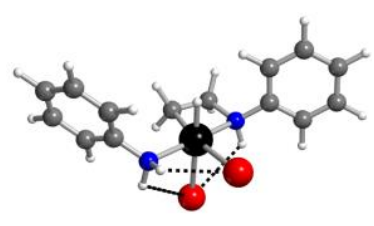

XLIII

$11.0(14.3)$

Figure 7. Optimized geometries and relative $\Delta \mathrm{G}^{\mathrm{CPCM}}$ in $\mathrm{kcal} \mathrm{mol}^{-1}$ at $298.15 \mathrm{~K}$ (and at $423.15 \mathrm{~K}$ in parentheses) for the lowest energy platina(IV)cyclic derivatives XXXVI and XLIII.

Since the addition of the monodentate ligands $\mathrm{Br}^{-}, \mathrm{PhNH}_{2}$ and $\mathrm{C}_{2} \mathrm{H}_{4}$ to 5 -coordinate $\mathrm{Pt}^{\mathrm{IV}}$ hydride complexes was generally found unfavourable (e.g. see Figure 5), a reasonable question is whether the 6-coordinate $\mathrm{Pt}^{\mathrm{IV}}$ complexes XXXIV-XLIV may gain stability by loss of one of these ligands to produce 5-coordinate derivatives. This possibility was probed only for the most stable $\mathrm{Pt}^{\mathrm{IV}}$ platinacyclic compounds XXXVI and XLIII, as well as XXXVIII. In particular, it may be predicted that the most easily lost ligand is located trans to one of the two strongly transdirecting lihands, namely $\mathrm{H}$ and the alkyl substituent. This procedure generated three new systems, a neutral $\left[\mathrm{PtHBr}_{2}\left(\kappa^{2}: \mathrm{C}, \mathrm{N}-\mathrm{CH}_{2} \mathrm{CH}_{2} \mathrm{NHPh}\right)\right]$ complex XLVII and two isomeric cationic complexes $\left[\mathrm{PtHBr}\left(\mathrm{PhNH}_{2}\right)\left(\kappa^{2}: \mathrm{C}, \mathrm{N}-\mathrm{CH}_{2} \mathrm{CH}_{2} \mathrm{NHPh}\right)\right]^{+}$XLVIII and IL (details in SI). The generation of neutral XLVII is much less unfavorable than the formation of the cationic 
derivatives XXXVIII and XLIII, but the most stable $\mathrm{Pt}^{\mathrm{IV}}$ platinacyclic system remains the anionic 6-coordinate XXXVI. This situation parallels that of the non cyclic $\mathrm{Pt}^{\mathrm{IV}}-\mathrm{H}$ systems (see Figure 5), although it is quantitatively more in favour of the 6-coordinate system. System $\mathbf{X X V}$, (Figure 5) remains the most stable 6-coordinate $\mathrm{Pt}^{\mathrm{IV}}-\mathrm{H}$ complex, though only marginally with respect to XXXVI (8.0 vs. $9.6 \mathrm{kcal} \mathrm{mol}^{-1}$ ), and system $\mathbf{X X}$ (Figure 4) remains the most stable 5coordinate $\mathrm{Pt}^{\mathrm{IV}}-\mathrm{H}$ complex. These will be the systems worth considering for the product liberation step (vide infra).

\section{(d) The rate-determining step.}

Reductive C-H elimination from $\mathrm{Pt}^{\mathrm{IV}}-\mathrm{H}$ aminoalkyl systems (B or $\mathbf{E}$ in Scheme 3) would produce the hydroamination product and regenerate $\mathrm{Pt}^{\mathrm{II}}$ intermediates. For instance, system $\mathbf{X X}$ would lead to 3-coordinate $\left[\mathrm{PtBr}_{3}\right]^{-}$, which can however be stabilized by the PhNHEt reductive elimination product, whereas $\mathbf{X X V}$, would lead to $\left[\mathrm{PtBr}_{3}\left(\mathrm{PhNH}_{2}\right)\right]^{-}$, III, and $\mathbf{X X X V I}$ would generate the related complex $\left[\mathrm{PtBr}_{3}(\mathrm{PhNHEt})\right]^{-}$. However, the hydroamination product may also be liberated by C-protonation of the aminoalkyl ligand in systems of type $\mathbf{A} / \mathbf{C}$ or $\mathbf{F}$ in Scheme 3. The proton source may be external (the anilinium ion, which is the strongest available acid in the aniline-rich medium) or internal (the ammonium function of the zwitterionic derivatives).

d1. Reductive elimination of PhNHEt from $\mathrm{Pt}^{I V}-H$ intermediates. This step was first explored starting from the most accessible 5-coordinate $\mathrm{Pt}^{\mathrm{IV}}$ hydride system $\mathbf{X X}$. The reaction coordinate led to a square planar $\mathrm{Pt}^{\mathrm{II}} \sigma$ complex $\mathbf{L}$ where the $\mathrm{PhEtNH}$ product remains bonded to Pt through a C-H bond through transition state TS(XX-L), see Figure 8 (for a more detailed scan of this coordinate, see the supplemental figure S6). The Pt-bonded C-H bond in $\mathbf{L}$ is slightly lengthened by the electronic interaction with the metal $(1.12 \AA$ vs. $1.09 \AA$ for the other two C-H 
bonds of the $\mathrm{CH}_{3}$ group) and shows a red-shifted $v_{\mathrm{C}-\mathrm{H}}$ vibration $\left(2723 \mathrm{~cm}^{-1}, c f .3161\left(v_{\mathrm{as}}\right)\right.$ and $3111\left(v_{\mathrm{s}}\right) \mathrm{cm}^{-1}$ for the $\mathrm{CH}_{2}$ group.

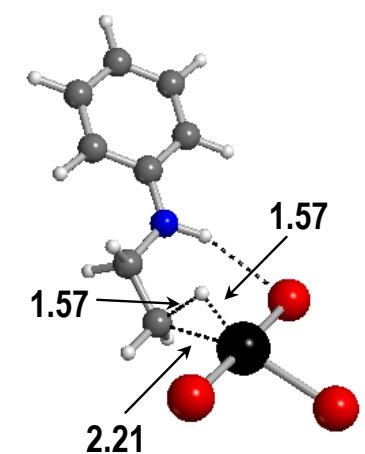

TS(XX-L)

$19.4(21.1)$

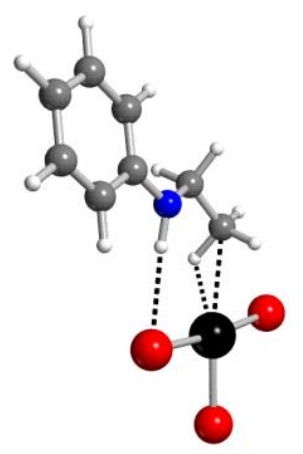

$\mathbf{L}$

$7.9(9.3)$

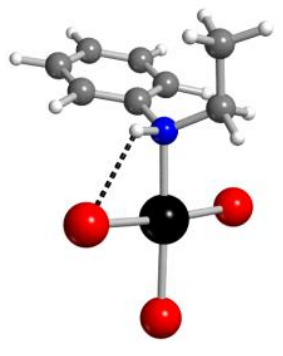

LI

$-13.3(-11.0)$

Figure 8. Optimized geometries and relative $\Delta \mathrm{G}^{\mathrm{CPCM}}$ in $\mathrm{kcal} \mathrm{mol}^{-1}$ at $298.15 \mathrm{~K}$ (and at 423.15 $\mathrm{K}$ in parentheses) for relevant structures along the $\mathrm{C}-\mathrm{H}$ reductive elimination from XX.

Interestingly, the $\mathrm{N}-\mathrm{H} \cdots \mathrm{Br}$ hydrogen bond is retained throughout the reductive elimination coordinate, the $\mathrm{H} \cdots \mathrm{Br}$ distance remaining confined in the narrow 2.516-2.630 $\AA$ range. The optimized transition state, $\mathbf{T S}(\mathbf{X X}-\mathbf{L})\left(756 \mathrm{i} \mathrm{cm}^{-1}\right)$, has essentially the same geometry $\left(d_{\mathrm{HC}}=1.57\right.$ $\AA$, $\left.d_{\mathrm{PtH}}=1.57 \AA, d_{\mathrm{PtC}}=2.21 \AA, \angle \mathrm{CPtBr}_{\mathrm{tr}}=160.4^{\circ}\right)$ and $\Delta \mathrm{G}^{\mathrm{CPCM}}$ value as the $\Delta \mathrm{G}^{\mathrm{CPCM}}$ maximum along the $\mathrm{C}-\mathrm{H}$ reductive elimination scan (figure $\mathrm{S} 6$ ), contrary to the intermolecular scans examined above for which the $\Delta \mathrm{G}^{\mathrm{CPCM}}$ is offset relative to the $\mathrm{E}$ maximum. This is because no major charge redistribution, thus no large entropic effect by solvation, occurs along this reaction coordinate. The $\sigma$ complex $\mathbf{L}$ may rearrange to a much more stable isomeric $\mathrm{N}$-bonded form, $\left[\mathrm{PtBr}_{3}(\mathrm{NHPhEt})\right]^{-}(\mathbf{L I}$, Figure 8$)$, which still features the intramolecular $\mathrm{N}-\mathrm{H} \cdots \mathrm{Br}$ interaction $\left(\mathrm{H} \cdots \mathrm{Br}=2.475 \AA\right.$ 的 $\left.\mathrm{Pt}-\mathrm{N}-\mathrm{H}=96.3^{\circ}\right)$. However, the coordination position occupied by the $\mathrm{C}-\mathrm{H} \sigma$ bond in $\mathbf{L}$ may also be taken directly by a new molecule of ethylene, to liberate the hydroamination product PhNHEt and regenerate the catalyst resting state II. This takes the system down to a $\Delta \mathrm{G}^{\mathrm{CPCM}}$ value of $-20.8 \mathrm{kcal} \mathrm{mol}^{-1}$ at $298.15 \mathrm{~K}$ and $-18.1 \mathrm{kcal} \mathrm{mol}^{-1}$ at $423.15 \mathrm{~K}$ 
(the calculated thermodynamic gain of the hydroamination reaction is -6.1 and $-3.6 \mathrm{kcal} \mathrm{mol}^{-1}$ at 298.15 K and 423.15 K, respectively).

A scan of the reductive elimination pathway starting from the anionic 6-coordinated complexes $\mathbf{X X V}$ and $\mathbf{X X V}$, were found to be associated to a stiff increase of $\Delta \mathrm{G}^{\mathrm{CPCM}}$ leading to transition states, $\mathbf{T S}(\mathbf{X X V})$ and $\mathbf{T S}\left(\mathbf{X X V}^{\prime} \mathbf{V}^{\prime}\right)$, respectively (see Figure 9), featuring a dramatically weakened bond to the ligand trans to $\mathrm{H}$ ( $\mathrm{Br}$ for $\mathbf{X X V}, \mathrm{Pt} \cdots \mathrm{Br}=2.83 \AA$; $\mathrm{PhNH}_{2}$ for $\mathbf{X X V}$, $\left.\mathrm{Pt} \cdots \mathrm{NH}_{2} \mathrm{Ph}=4.19 \AA\right)$. The $\mathbf{T S}(\mathbf{X X V})$ system appears to evolve toward a $\left[\mathrm{PtBr}_{2}\left(\mathrm{PhNH}_{2}\right)\left(\eta^{2}-\mathrm{H}-\right.\right.$ $\left.\left.\mathrm{CH}_{2} \mathrm{CH}_{2} \mathrm{NHPh}\right)\right]$ and a separated $\mathrm{Br}^{-}$ion, whereas the $\mathbf{T S}\left(\mathbf{X X V} \mathbf{V}^{\prime}\right)$ corresponds very closely to the geometry of TS(XX-L) with an H-bonded aniline molecule ( $c f$. Figure 8 and Figure 9). The energies of these transition states are much greater than that of $\mathbf{T S}(\mathbf{X X}-\mathbf{L})$ on the $\Delta \mathrm{G}^{\mathrm{CPCM}}$ scale. The energy of $\mathbf{T S}\left(\mathbf{X X \mathbf { X } ^ { \prime }}\right)$ seems too high, considering that it is essentially an H-bonded adduct of TS(XX-L) with aniline. However, correction of this term for H-bonding in the aniline starting material $\left(\Delta \mathrm{G}^{\mathrm{CPCM}}{ }_{c o r}\right.$ scale) bring this energy much closer, though still higher, than that of TS(XX-L). In a similar fashion, the reductive elimination coordinate from complex XXXVI leads to a severe weakening of the Pt-Br bond trans to $\mathrm{H}$, transforming the system to a square planar $\sigma$ complex where the PhEtNH product remains bonded to $\mathrm{Pt}$ through a $\mathrm{C}-\mathrm{H}$ bond. The maximum along this coordinate $(\mathrm{C} \cdots \mathrm{H}=1.7 \AA)$, also shown in Figure 9 , has a relative $\Delta \mathrm{G}^{\mathrm{CPCM}}$ of $23.4 \mathrm{kcal} \mathrm{mol}^{-1}$, ca. $4.0 \mathrm{kcal} / \mathrm{mol}$ higher than the reductive elimination transition state from $\mathbf{X X}$. The energy profiles of the two processes involving the isomeric systems XX and XXXVI are compared in Figure S7. Given these results, the elimination process from the other 6-coordinate systems shown in Figure 5 was not further investigated. 


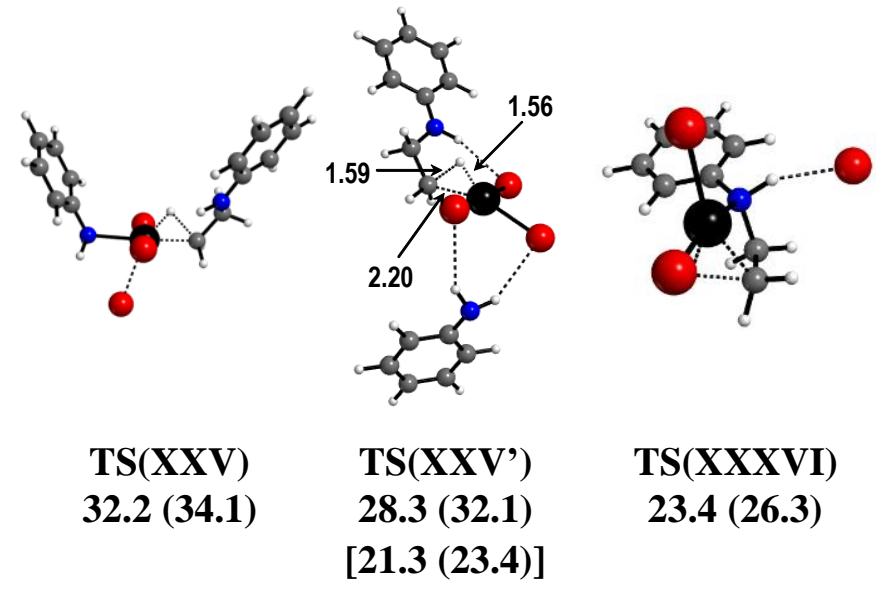

Figure 9. Optimized geometry of the reductive elimination transition states from systems $\mathbf{X X V}, \mathbf{X X V}$ ' and XXXVI, with relative $\Delta \mathrm{G}^{\mathrm{CPCM}}$ in $\mathrm{kcal} \mathrm{mol}^{-1}$ at $298.15 \mathrm{~K}$ (and at 423.15 $\mathrm{K}$ in parentheses). The values in brackets correspond to $\Delta \mathrm{G}^{\mathrm{CPCM}}$ cor (see text).

d2. Protonolysis of the alkyl ligand. It is possible to envisage four different ways to accomplish this process, two inter- and two intramolecular as depicted in Scheme 4. Pathway (a1) requires prior deprotonation of the zwitterionic intermediate, followed by C-protonation of the resulting aminoalkyl ligand. The direct protonolysis of the zwitterionic intermediate by anilinium (pathway (a2)) should be less favorable than (a1) because of the Coulombic bias of the ammonium charge. Therefore, only pathway (a1) has been considered in the calculations. Pathway (b1) is a direct intramolecular transfer of the anilinium proton to the alkyl carbon atom. Finally, the intramolecular proton shuttle pathway (b2), which is a variant of (b1) and also a concerted version of the two-step (a1) pathway, was proposed as the lowest-energy pathway from the model investigation of the addition of $\mathrm{NH}_{3}$ to $\mathrm{C}_{2} \mathrm{H}_{4}$ catalyzed by $\left[\mathrm{PtCl}\left(\mathrm{PH}_{3}\right)_{2}\right]^{+} .32$ Pathway (a1) did not lead to any low-energy pathway for the release of the hydroamination product on the free energy scale. Therefore, a detailed account of our work on this pathway is presented in the Supporting Information. The lowest energy transition states for the proton transfer from $\mathrm{PhNH}_{3}{ }^{+}$to $\mathbf{X X X I I}$ (the lowest $\Delta \mathrm{G}^{\mathrm{CPCM}}$ systems amongst all the deprotonated zwitterions) or XXIX, leading to cis- $\mathrm{PtBr}_{2}\left(\mathrm{C}_{2} \mathrm{H}_{4}\right)(\mathrm{PhNHEt})$ and trans- $\mathrm{PtBr}_{2}\left(\mathrm{PhNH}_{2}\right)(\mathrm{PhNHEt})$ 
products where the PhNHEt ligand is coordinated as a $\sigma-\mathrm{C}-\mathrm{H}$ complex, are shown in Figure 10 (TS(LII'-LIII) and TS(LIV-LV), respectively).

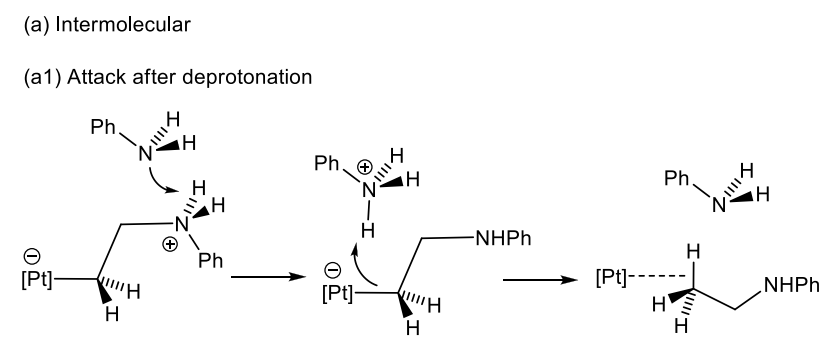

(a2) Direct attack by an external acid

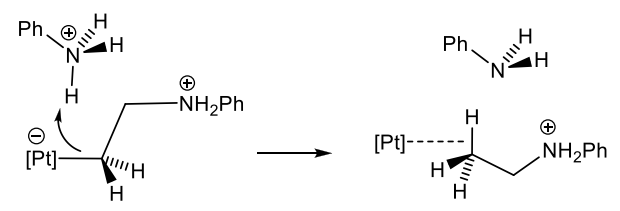

(b) Intramolecular

(b1) Direct

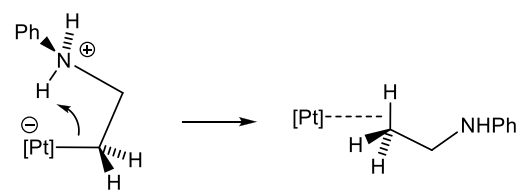

(b2) Proton shuttle via an additional amine molecule<smiles>CC(C)[C@H](C)CNc1ccccc1</smiles>

Scheme 4. Possible pathways for Pt-C bond protonolysis.

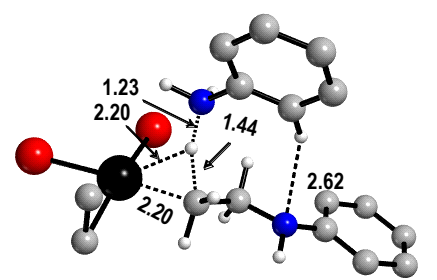

TS (LII'-LIII)

34.4

[27.3]

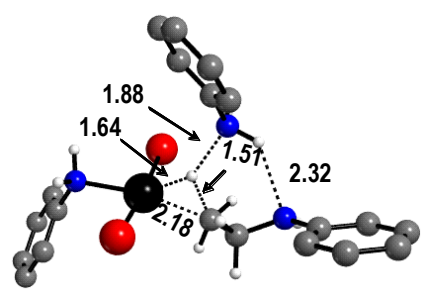

TS (LIV-LV)

34.0

[27.0]

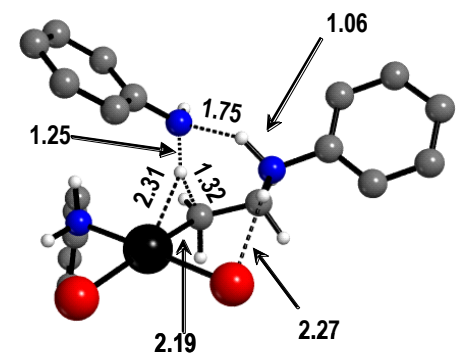

TS(LVI-LVII)

37.6 (39.5)

[30.1 (31.0]

Figure 10. Relevant geometries of transition states along C-protonation pathways, with their relative $\Delta \mathrm{G}^{\mathrm{CPCM}}$ in $\mathrm{kcal} \mathrm{mol}^{-1}$ at $298.15 \mathrm{~K}$ (and at $423.15 \mathrm{~K}$ in parentheses). In brackets.... 
Pathway (b1) was explored for complex IX. This choice is justified by the fact that this is the most electron-rich zwitterion, leading to the lowest energy 5-coordinate $\mathrm{Pt}^{\mathrm{IV}}-\mathrm{H}$ system by proton transfer to Pt. It may be argued that direct proton transfer to the adjacent alkyl $\mathrm{C}$ atom is regulated by the same electronic effects and should therefore also be easiest for the most electron-rich system. Proton transfer leads to system $\mathbf{L}$, namely the same $\sigma$-complex that was previously shown to result from reductive elimination via the hydride intermediate $\mathbf{X X}$. A STQN calculation between complexes $\mathbf{I X}$ and $\mathbf{L}$ converged to the same transition state of the reductive elimination pathway, TS(XX-L). Hence, this pathway does not exist as such, at least for this specific system. Indeed, the optimized TS(XX-L) has only one imaginary frequency ( $1^{\text {st }}$ order saddle point) and an IRC calculation leads to the $\mathbf{X X}$ and $\mathbf{L}$ local minima.

Finally, pathway (b2) was checked for the lowest energy zwitterionic intermediate XIII, but also from the related system XI. Transition states were located for both systems (the latter, TS(LVI-LVII), is shown in Figure 10, full details are given in the Supporting Information), but the energy values are once again prohibitively high (> $10 \mathrm{kcal} \mathrm{mol}^{-1}$ greater) in comparison to the reductive elimination pathway from the $\mathrm{Pt}^{\mathrm{IV}}-\mathrm{H}$ intermediate $\mathbf{X X}$.

Note that the three transition states shown in Figure 10 are actually less disfavored than $\mathbf{T S}(\mathbf{X X}-\mathbf{L})$ on the electronic energy scale, the $\Delta \mathrm{E}^{\mathrm{CPCM}}$ relative to the resting state II being (in kcal $\mathrm{mol}^{-1}$ ): 0.0 for TS(LII'-LIII), -1.1 for TS(LIV-LV), 2.0 for TS(LVI-LVII), vs. 3.7 for TS(XX-L). However, all these proton transfer pathways require the intervention of a second species $\left(\mathrm{PhNH}_{3}{ }^{+}\right.$or $\left.\mathrm{PhNH}_{2}\right)$ with an inevitable additional entropic penalty. Even if the condensed phase entropic contribution is partially quenched and the calculation of $\Delta \mathrm{G}^{\mathrm{CPCM}}$ as carried out in the present contribution certainly overestimates it, the margin in favor of $\mathbf{T S}(\mathbf{X X}-\mathbf{L})$ appears too large to be accounted for by this approximation. Indeed, treatment of the solution free energy according to the $\Delta \mathrm{G}^{\mathrm{CPCM}}$ cor approach, as already detailed above in section (a), which equalizes the number of species involved on each side of the chemical equation, yields the values shown in 
brackets in Figure 10, still higher than that of $\mathbf{T S}(\mathbf{X X}-\mathbf{L})$. Therefore, these proton shuttle pathways do not appear to be competitive, at least for the present system, contrary to the conclusion made for the $\mathrm{NH}_{3}$ addition to $\mathrm{C}_{2} \mathrm{H}_{4}$ catalyzed by $\left[\mathrm{PtCl}\left(\mathrm{PH}_{3}\right)_{2}\right]^{+}{ }^{32}$ Note, however, that the latter study was based only on the electronic energy without consideration of the entropic contribution.

\section{Discussion}

At the chosen level of theory, the computational investigation of the $\mathrm{PtBr}_{2} / \mathrm{Br}^{-}-$catalyzed aniline addition to ethylene rules out an amine activation pathway and validates the olefin activation pathway. In agreement with previous arguments that were based on the catalytic studies and with recent solution equilibrium studies, the calculations indicate complex $\left[\mathrm{PtBr}_{3}\left(\mathrm{C}_{2} \mathrm{H}_{4}\right)\right]^{-}$(II) as the most stable species under catalytic conditions (catalyst resting state). Many other $\mathrm{Pt}^{\mathrm{II}}$ complexes accessible by ligand exchange equilibria (I and III-VIII), some of which have been isolated and characterized, ${ }^{49}$ are off-loop equilibrium species located at relatively low energies. The lowest energy pathway of the catalytic cycle starting from the resting state and ending at the same point on the subsequent cycle is summarized in Figure 11. 


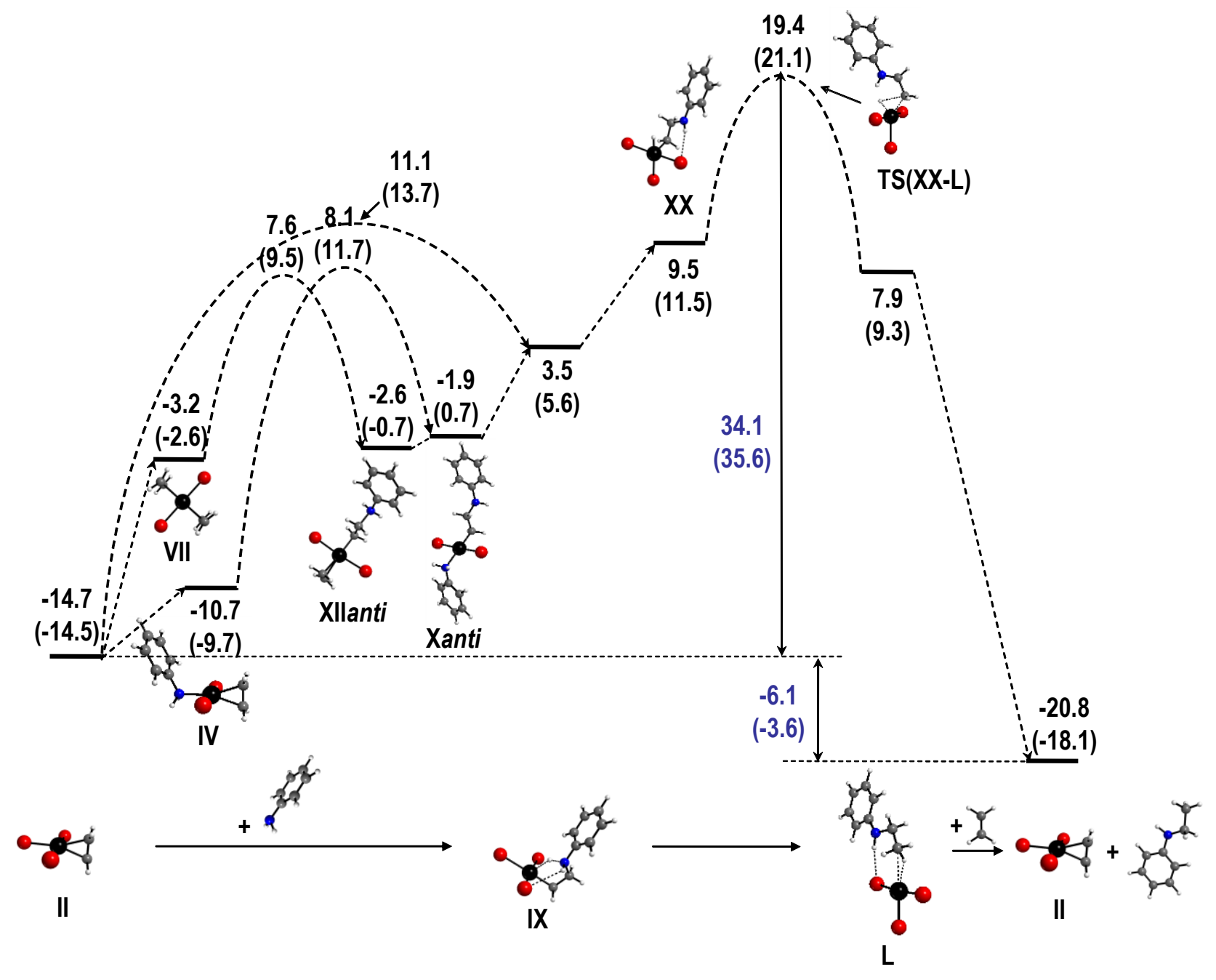

Figure 11. Lowest-energy pathway for $\mathrm{PtBr}_{2} / \mathrm{Br}^{-}$-catalyzed addition of aniline to ethylene. Values are $\Delta \mathrm{G}^{\mathrm{CPCM}}$ relative to $\mathbf{I}$ in $\mathrm{kcal} \mathrm{mol}^{-1}$ at $298.15 \mathrm{~K}$ (and at $423.15 \mathrm{~K}$ in parentheses)

The productive cycle starts with the aniline nucleophilic addition to the anti face of the ethylene ligand in II. Although the addition barrier for any of the $\mathrm{Pt}^{\mathrm{II}}-\mathrm{C}_{2} \mathrm{H}_{4}$ complexes is lower than the rate-determining step of the overall cycle ( $c f$. Figure 2) and the resulting products (notably Xanti and XIIanti) will be present as off-loop species, only the zwitterionic complex $\left[\mathrm{PtBr}_{3}\left(\mathrm{CH}_{2} \mathrm{CH}_{2} \mathrm{NH}_{2} \mathrm{Ph}\right)\right]^{-}, \mathbf{I X}$, leads to the product release channel. In agreement with a previous proposal, ${ }^{26}$ the aniline addition to $\left[\mathrm{PtBr}_{2}\left(\mathrm{C}_{2} \mathrm{H}_{4}\right)\left(\mathrm{PhNH}_{2}\right)\right]$ is actually easier, although only for the trans isomer $\mathbf{I V}$, leading to $\mathbf{X}$, whereas the cis isomer $\mathbf{V}$ leads to a higher barrier. The lowest addition barrier is in fact that to trans- $\mathrm{PtBr}_{2}\left(\mathrm{C}_{2} \mathrm{H}_{4}\right)_{2}$ (VII) leading to XII. However, all these 
alternative zwitterionic intermediates, even though more stable than $\mathbf{I X}$, do not lead to the liberation of the hydroamination product by lower energy pathways and can only proceed by transforming back to IX by ligand exchange processes. In our previous contribution ${ }^{49}$ we have failed to experimentally observe the zwitterionic complexes resulting from $\mathrm{PhNH}_{2}$ addition to ethylene in the isolated complexes $\mathbf{2 , 4}$ and 5. The calculated energy differences between the addition products and the starting compounds $\left(18.2 \mathrm{kcal} \mathrm{mol}^{-1}\right.$ for II, $8.8 \mathrm{kcal} \mathrm{mol}^{-1}$ for $\mathbf{I V}$ and $9.7 \mathrm{kcal} \mathrm{mol}^{-1}$ for $\mathbf{V}$, Figure 2) do not allow a sufficient equilibrium population of the zwitterionic complexes to be present for detection, in qualitative agreement with the experiment. Note also the previously reported failure to observe an addition compound when trans$\left[\mathrm{Pt}\left(\mathrm{C}_{2} \mathrm{H}_{4}\right)\left(\mathrm{Et}_{2} \mathrm{NH}\right) \mathrm{Cl}_{2}\right]$ was reacted with aniline, ${ }^{80,}{ }^{81}$ contrary to $\mathrm{Et}_{2} \mathrm{NH}^{84}$ The experimental observation of zwitterionic products for $\mathrm{Pt}^{\mathrm{II}}$ appears limited to amines of sufficient basicity ( $\mathrm{pK}_{\mathrm{a}}$ $>5$ for the conjugate ammonium ion).

The catalytic cycle continues with transfer of the ammonium proton in $\mathbf{I X}$ to the Pt center, to produce a 5-coordinate $\mathrm{Pt}^{\mathrm{IV}}-\mathrm{H}$ complex, $\left[\mathrm{Pt}(\mathrm{H}) \mathrm{Br}_{3}\left(\mathrm{CH}_{2} \mathrm{CH}_{2} \mathrm{NHPh}\right)\right]^{-}, \mathbf{X X}$. This equilibrates with a number of 18-electron ligand adducts, of which the most stable is the aniline adduct, $\left[\mathrm{Pt}(\mathrm{H}) \mathrm{Br}_{3}\left(\mathrm{PhNH}_{2}\right)\left(\mathrm{CH}_{2} \mathrm{CH}_{2} \mathrm{NHPh}\right)\right]^{-}, \mathbf{X X V}$, with a mer arrangement of the three $\mathrm{Br}^{-}$ligands and with the aniline ligand trans to $\mathrm{H}$ (see Figure 5). Most of these saturated derivatives are in fact less stable than the unsaturated $\mathbf{X X}$ precursor on the $\Delta \mathrm{G}^{\mathrm{CPCM}}$ scale, which is not surprising because two ligands with a strong trans labilizing effect are present (the hydride and the ammonium-bearing alkyl chain). In addition, the bromide ligands may provide a certain degree of stabilization of electronic unsaturation through $\pi$ donation. ${ }^{100}$ Examples of stable 5-coordinate $\mathrm{d}^{6}$ complexes are indeed quite common for $\mathrm{Rh}^{\mathrm{III}}$ and $\mathrm{Ir}^{\mathrm{III}}$ complexes, such as $\mathrm{M}(\mathrm{H}) \mathrm{Cl}($ pincer$)(\mathrm{M}$ $\left.=\mathrm{Rh},{ }^{101-103} \operatorname{Ir}^{104-107}\right)$ or $\mathrm{M}(\mathrm{H})_{2} \mathrm{Cl}(\mathrm{L})_{2}\left(\mathrm{M}=\mathrm{Rh},{ }^{108,109} \mathrm{Ir}^{110,111}\right)$, but at least one example also exists for $\mathrm{Pt}^{\mathrm{IV}}$, e.g. $\mathrm{PtBr}\left(\mathrm{CH}_{3}\right)_{2}(\mathrm{acac}) .{ }^{112}$ All the saturated ligand adducts (XXIII-XXV) are located at lower energy than the barrier of the rate-determining step and are therefore additional off-loop species. Other 5-coordinate $\mathrm{Pt}^{\mathrm{IV}}-\mathrm{H}$ complexes, accessible from the other zwitterionic 
intermediates (e.g. XXI-XXII, Figure 4) are located at higher energy and do not provide suitable pathways for product liberation.

Several other off-loop species (at lower energy than the rate-determining barrier but not directly involved in the minimum-energy pathway of the catalytic cycle) are selected squareplanar $\mathrm{Pt}^{\mathrm{II}}$ complexes obtained by deprotonation of selected zwitterionic complexes (XXIX, XXXI and XXXII, Figure 6), square-planar $\mathrm{Pt}^{\mathrm{II}}$ complexes with a platinaazacyclobutane ring derived from the latter by substitution of a bromide ligand with the dangling amine function of the aminoalkyl ligand (XXXIII-XXXV), and $\mathrm{Pt}^{\mathrm{IV}}-\mathrm{H}$ complexes with a platinaazacyclobutane ring (either 6-coordinated, XXXVI-XLVI, or 5-coordinated, e.g. XLVII). Metallaazacyclobutadiene complexes of $\mathrm{Pt}^{\mathrm{II}}$ were indeed obtained by deprotonation of zwitterionic products resulting from the addition of basic amines to coordinated ethylene or other olefins (process $\mathbf{A}($ or $\mathbf{C}) \rightarrow \mathbf{F} \rightarrow \mathbf{D}$ in Scheme 3), ${ }^{84,88}$ some of them being crystallographically characterized. ${ }^{86,89,90}$ Our study confirms the accessibility of these derivatives under appropriate experimental conditions, but shows that they are only off-loop species and not catalytic intermediates (none of these complexes leads to product liberation by a low-energy pathway), at least for the aniline addition to ethylene with this $\mathrm{PtBr}_{2} / \mathrm{Br}^{-}$catalytic system.

Of the two possible ways to liberate the hydroamination product, namely reductive elimination from a $\mathrm{Pt}^{\mathrm{IV}}$ hydrido-aminoalkyl derivative and protonolysis of a $\mathrm{Pt}^{\mathrm{II}}$ aminoalkyl derivative, the first one seems preferred for this catalytic cycle. The lowest-energy pathway, shown in Figure 11, involves elimination from complex $\mathbf{X X}$, with the rate-determining transition state $\mathbf{T S}(\mathbf{X X}-\mathbf{L})$ located $34.1 \mathrm{kcal} \mathrm{mol}^{-1}$ higher than the resting state on the $\Delta \mathrm{G}^{\mathrm{CPCM}}$ scale at 298.15 K (35.6 kcal mol-1 at $423.15 \mathrm{~K})$. This value appears in reasonable agreement with the experimental evidence. Although a detailed kinetic and temperature-dependent study was not carried out (this would be hampered by the observed catalyst deactivation process at the high temperatures required by the reaction $)^{24,113}$ an upper estimate of the activation barrier can be calculated from the observed initial TOF of $37 \mathrm{~h}^{-1}$ at $150{ }^{\circ} \mathrm{C},{ }^{24}$ namely $28.9 \mathrm{kcal} / \mathrm{mol}$. The 
disagreement is not too large and the discrepancy may be attributed to the approximations involved (nature of functional, solvent model, proper treatment of solvation entropy, neglect of ion pair interactions, etc.). The reductive elimination pathway from 6-coordinate hydridoaminoalkyl $\mathrm{Pt}^{\mathrm{IV}}$ derivatives involves the concerted dissociation of the ligand located trans to $\mathrm{H}$, leading to a much greater barrier for systems where this ligand is $\mathrm{Br}^{-}$(XXV and XXXVI) because of the charge separation. However, even when this ligand is the less strongly bonded and neutral $\mathrm{PhNH}_{2},\left(\mathbf{X X V ^ { \prime }}\right)$, the transition state [TS(XXV')] has a greater energy. It is thus clear that reductive elimination is more favourable from the 5-coordinate $\mathbf{X X}$ than from the more stable 6coordinate complexes. It is indeed known that reductive elimination in octahedral $\mathrm{d}^{6}$ systems is facilitated by a preliminary ligand dissociation to yield a 16-electron 5-coordinate intermediate, with examples known for $\mathrm{Rh}^{\mathrm{III}},{ }^{114} \mathrm{Ir}^{\mathrm{III}},{ }^{28}$ and also $\mathrm{Pt}^{\mathrm{IV}} \cdot{ }^{115,} 116$

A direct protonolysis of the $\mathrm{Pt}^{\mathrm{II}}$-bonded aminoalkyl ligand, either intermolecular by anilinium or intramolecular by the ammonium function in the zwitterionic intermediate, does not lead to a lower-energy pathway for product liberation. The lowest pathway corresponds to the reductive elimination from the zwitterion $\mathbf{I X}$ through the hydride $\mathbf{X X}$ and transition state TS(XX-L). Hence, the electron density of the Pt-C bond in this system favours transfer of the proton to the $\mathrm{Pt}$ atom, to yield a well defined $\mathrm{Pt}^{\mathrm{IV}}-\mathrm{H}$ local minimum, rather than directly to the $\mathrm{C}$ atom to directly yield the $\sigma$-complex $\mathbf{L}$, which is also the product of the reductive elimination, in a single step. The introduction of an additional aniline molecule to assist this proton transfer through a shuttle mechanism does not alter this preference for proton transfer to the metal site. Note that the direct pathway of proton transfer to the aminoalkyl $\mathrm{C}$ atom, assisted by an extra molecule of free amine, was found to be the preferred pathway for the model study of the $\mathrm{NH}_{3}$ addition to $\mathrm{C}_{2} \mathrm{H}_{4}$ catalyzed by $\left[\mathrm{PtCl}\left(\mathrm{PH}_{3}\right)_{2}\right]^{+} .{ }^{32}$ The difference between the two pathways is expected to depend on the polarity of the Pt-C bond in the zwitterionic intermediate, which should rather be in favour of the $\mathrm{C}$ atom if the coordination sphere is less electron-donating, especially if the complex is positively charged, and more in favour of the Pt atom with more 
electron-donating ligands, especially if the complex is negatively charged. In the end, however, the product is the same, a $\sigma$-complex with the hydroamination product bonded to the catalytic metal through a C-H bond (Scheme 5). Even when the proton transfer proceeds directly from the $\mathrm{N}$ to the $\mathrm{C}$ atom, is it somewhat assisted by the $\mathrm{Pt}$ atom with a significant $\mathrm{Pt} \cdots \mathrm{H}$ interaction at the transition state level. ${ }^{32}$
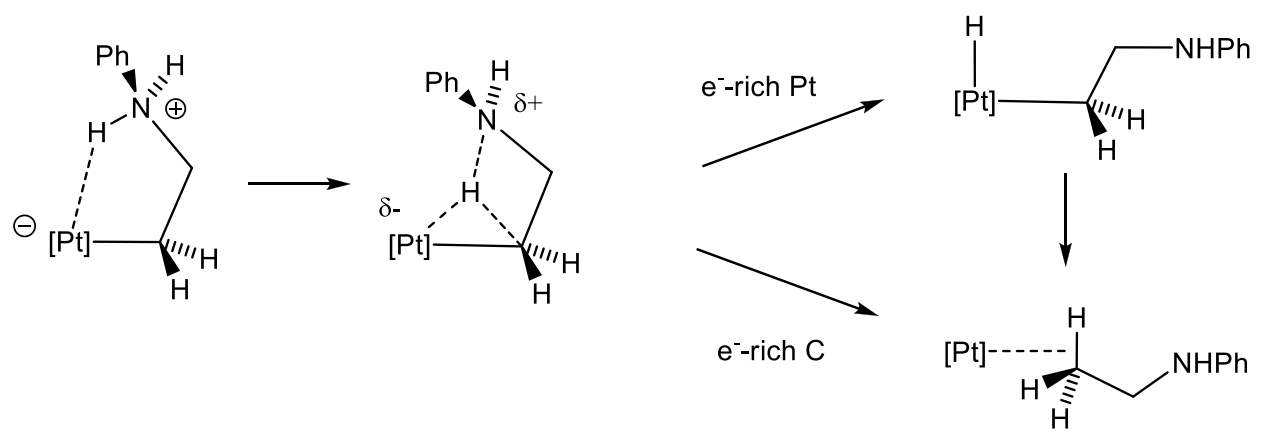

Scheme 5. Competition between the $\mathrm{Pt}$ and $\mathrm{C}$ atoms in the $\mathrm{Pt}-\mathrm{C}$ bond for proton capture.

The catalytic cycle is completed by liberation of the hydroamination product PhNHEt from the $\sigma$-complex L. A possible first event is rearrangement of the PhNHEt ligand to yield a Nbonded isomer $\mathbf{L I}$, which is significantly more stable. When comparing the relative energies of LI and III (-13.3 vs. $-10.7 \mathrm{kcal} / \mathrm{mol})$, the stronger donating power of $\mathrm{PhEtNH}$ relative to $\mathrm{PhNH}_{2}$ is clearly evidenced. However, coordination of ethylene is even more favourable, in agreement with experimental equilibrium studies. ${ }^{49}$ Hence, the $\kappa^{2}-C, H$-bonded PhNHEt ligand may be directly replaced by a new ethylene molecule to regenerate the resting state II and start a new cycle. According to this result and contrary to an earlier suggestion, ${ }^{24}$ the formation of the hydroamination product should not lead to catalyst poisoning. Rather, as confirmed by more recent studies, the observed reduction of activity is attributable to catalyst deactivation by reduction to the metallic state. ${ }^{113}$

\section{Conclusions}


We have reported in this paper a comprehensive investigation of the full catalytic cycle for the $\mathrm{N}-\mathrm{H}$ addition of aniline to ethylene (hydroamination) catalyzed by the $\mathrm{PtBr}_{2} / \mathrm{Br}^{-}$system. It is the first theoretical investigation that addresses the real catalytic system, with the electronic effect of the amine substituent and real nature of the transition metal complex being included in the calculation. The study confirms the general proposition that the olefin activation mechanism is preferred over the amine activation mechanism for this metal, since the $\mathrm{N}-\mathrm{H}$ oxidative addition process yields $\mathrm{Pt}^{\mathrm{IV}}(\mathrm{H})$ (amido) intermediates that are found too high in energy. The mechanism essentially follows the same basic steps illustrated by the previous investigations by Senn et al. on the model $\mathrm{NH}_{3}$ addition to $\mathrm{C}_{2} \mathrm{H}_{4}$ catalyzed by $\left[\mathrm{PtCl}\left(\mathrm{PH}_{3}\right)_{2}\right]^{+}$, with the important difference that the key proton transfer from the zwitterionic intermediate ${ }^{-}\left[\mathrm{Pt}^{\mathrm{II}}\right]-\mathrm{CH}_{2} \mathrm{CH}_{2} \mathrm{NHRR}^{\prime+}$ to the $\mathrm{C}$ atom does not proceed directly, with or without the assistance by a free amine molecule (proton shuttle), but rather through the Pt atom and through an additional intermediate, a 5-coordinated $\left.\left[\mathrm{Pt}^{\mathrm{IV}}\right](\mathrm{H})\left(\mathrm{CH}_{2} \mathrm{CH}_{2} \mathrm{NRR}^{\prime}\right)\right]$ system which further proceeds by reductive elimination.

The study has also explored alternative processes that may occur on the zwitterionic intermediate, leading to products such as platinacyclic derivatives, both for $\mathrm{Pt}^{\mathrm{II}}$ and $\mathrm{Pt}^{\mathrm{IV}}$, that have indeed been experimentally observed under certain circumstances (amine basicity, ligand coordination sphere). These are found to be related to the hydroamination catalytic cycle as offloop species but do not directly lead to liberation of the hydroamination product. The study, however, has not addressed one important point of the hydroamination reaction, namely catalyst deactivation by reduction to $\mathrm{Pt}^{0}$. Indeed, it has been shown that anilines may act as reducing agents toward platinum complexes. ${ }^{117}$ Further, all known zwitterionic complexes of type $-\mathrm{PtCH}_{2} \mathrm{CH}_{2} \mathrm{NHR}_{2}{ }^{+}$, generated in situ from $\mathrm{Pt}^{\mathrm{II}} \mathrm{X}_{2}\left(\mathrm{C}_{2} \mathrm{H}_{4}\right) \mathrm{L}(\mathrm{X}=$ halogen $)$ and basic amines $\mathrm{NHR}_{2}$, are unstable and slowly decompose upon standing, in some cases with $\mathrm{Pt}^{0}$ formation. ${ }^{99,118}$ Such decomposition may also be triggered by N-H deprotonation, since the free amine can then promote $\beta$-hydride elimination to generate Pt-iminium complexes, ${ }^{99}$ in addition to the other 
pathways explored in this contribution. Indeed, the observed "promoting" effect of added strong acids could be explained by retardation of catalyst decomposition, rather than by the increase of the turnover frequency. Reduction to $\mathrm{Pt}^{0}$ has always been observed in the experimental studies carried out with this particular catalytic system $6,24,25,49,113$ and finding conditions that would prevent this decomposition is a major challenge for improving this catalytic system. Our experimental studies are continuing in this direction.

Other useful information that emerges from the current theoretical investigation is the identification of the dormant species, the $\left[\mathrm{PtBr}_{3}\left(\mathrm{C}_{2} \mathrm{H}_{4}\right)\right]^{-}$system II, and the transition state of the reductive elimination, $\mathbf{T S}(\mathbf{X X}-\mathbf{L})$. We are now in a position to zoom into these two key structures of the potential energy surface, since the free energy difference between them determines the TOF and hence the catalytic activity, by probing the effect of structural variations (e.g. nature of the halogen, amine substituents), guiding us toward the conception of more efficient catalytic processes.

Acknowledgement. We are grateful to the Centre National de la Recherche Scientifique (CNRS) and the Agence Nationale de la Recherche (ANR, Grant No. NT09_442499) for financial support and the MENESR (Ministère de l'Éducation Nationale, de l'Enseignement Supérieur et de la Recherche, France) for a Ph.D. fellowship to PD.

Supporting Information Available. Views of all optimized structures, tables of energy data and Cartesian coordinates for all optimized compounds, and description of less important computational details as referred to in the article (41 pages). This information is available free of charge via the Internet at http://pubs.acs.org/.

\section{References}

1 Müller, T. E.; Beller, M., Chem. Rev. 1998, 98, 675-703. 
Brunet, J.-J.; Neibecker, D., Catalytic Heterofunctionalization. ed.; VCH: Weinheim, 2001; 'Vol.' p 91-141.

Müller, T. E.; Hultzsch, K. C.; Yus, M.; Foubelo, F.; Tada, M., Chem. Rev. 2008, 108, 3795-3892.

Coulson, D. R., Tetrahedron Lett. 1971, 429-430.

Coulson, D. R., US 3,758,586 1973.

Baudequin, C.; Brunet, J.-J.; Rodriguez-Zubiri, M., Organometallics 2007, 26, 52645266.

Hong, S.; Marks, T. J., Acc. Chem. Res. 2004, 37, 673-686.

Ryu, J. S.; Li, G. Y.; Marks, T. J., J. Am. Chem. Soc. 2003, 125, 12584-12605.

Gardner, D. M.; Clark, R. T., US 4,454,321 1984.

Gardner, D. M.; Clark, R. T., EP 39,061 1981.

Schaffrath, H.; Keim, W., J. Mol. Catal. A 2001, 168, 9-14.

Yi, C. S.; Yun, S. Y., Org. Lett. 2005, 7, 2181-2183.

Krukowka, E.; Taube, R.; Steinborn, D., DD 296,909 1991.

Giner, X.; Najera, C., Synlett 2009, 3211-3213.

Liu, X. Y.; Li, C. H.; Che, C. M., Org. Lett. 2006, 8, 2707-2710.

Zhang, J. L.; Yang, C. G.; He, C., J. Am. Chem. Soc. 2006, 128, 1798-1799.

Zhang, Z. B.; Lee, S. D.; Widenhoefer, R. A., J. Am. Chem. Soc. 2009, 131, 5372-5373.

Giner, X.; Najera, C., Org. Lett. 2008, 10, 2919-2922.

Diamond, S. E.; Mares, F.; Szalkiewicz, A., Fundam. Res. Homog. Catal. 1979, 3, $345-$ 358.

Diamond, S. E.; Mares, F., US 4,215,218 1980.

Wang, X.; Widenhoefer, R. A., Organometallics 2004, 23, 1649-1651.

Karshtedt, D.; Bell, A. T.; Tilley, T. D., J. Am. Chem. Soc. 2005, 127, 12640-12646.

Mcbee, J. L.; Bell, A. T.; Tilley, T. D., J. Am. Chem. Soc. 2008, 130, 16562-16571.

Brunet, J. J.; Cadena, M.; Chu, N. C.; Diallo, O.; Jacob, K.; Mothes, E., Organometallics 2004, 23, 1264-1268.

Brunet, J. J.; Chu, N. C.; Diallo, O., Organometallics 2005, 24, 3104-3110.

Rodriguez-Zubiri, M.; Anguille, S.; Brunet, J.-J., J. Mol. Catal. A 2007, 271, 145-150.

Brunet, J.-J.; Chu, N.-C.; Rodriguez-Zubiri, M., Eur. J. Inorg. Chem. 2007, 4711-4722.

Casalnuovo, A. L.; Calabrese, J. C.; Milstein, D., J. Am. Chem. Soc. 1988, 110, 6738-

6744.

Zhou, J.; Hartwig, J. F., J. Am. Chem. Soc. 2008, 130, 12220-12221.

Chianese, A. R.; Lee, S. J.; Gagne, M. R., Angew. Chem., Int. Ed. Engl. 2007, 46, 40424059.

Kovacs, G.; Ujaque, G.; Lledós, A., J. Am. Chem. Soc. 2008, 130, 853-864.

Senn, H. M.; Blochl, P. E.; Togni, A., J. Am. Chem. Soc. 2000, 122, 4098-4107.

Tsipis, C. A.; Kefalidis, C. E., J. Organomet. Chem. 2007, 692, 5245-5255.

Vo, L. K.; Singleton, D. A., Org. Lett. 2004, 6, 2469-2472.

Patil, N. T.; Lutete, L. M.; Wu, H. Y.; Pahadi, N. K.; Gridnev, I. D.; Yamamoto, Y., J. Org. Chem. 2006, 71, 4270-4279.

Senn, H. M. Transition-metal-catalysed hydroamination of alkenes: theoretical studies using $a b$ initio molecular dynamics. Ph.D. Thesis, Swiss Federal Institute of Technology, Zurich, 2001.

Barrett, A. G. M.; Brinkmann, C.; Crimmin, M. R.; Hill, M. S.; Hunt, P.; Procopiou, P. A., J. Am. Chem. Soc. 2009, 131, 12906-12907.

Tobisch, S., Dalton Trans. 2006, 4277-4285.

Tobisch, S., Chem. Eur. J. 2007, 13, 4884-4894.

Tobisch, S., Chem. Eur. J. 2008, 14, 8590-8602.

Müller, C.; Koch, R.; Doye, S., Chem. Eur. J. 2008, 14, 10430-10436.

Motta, A.; Lanza, G.; Fragalà, I. L.; Marks, T. J., Organometallics 2004, 23, 4097-4104. 
Tobisch, S., Chem. Eur. J. 2005, 11, 6372-6385.

Tobisch, S., J. Am. Chem. Soc. 2005, 127, 11979-11988.

Tobisch, S., Chem. Eur. J. 2006, 12, 2520-2531.

Motta, A.; Fragala, I. L.; Marks, T. J., Organometallics 2006, 25, 5533-5539.

Hunt, P. A., Dalton Trans. 2007, 1743-1754.

Tobisch, S., Chem. Eur. J. 2007, 13, 9127-9136.

Dub, P. A.; Rodriguez-Zubiri, M.; Daran, J.-C.; Brunet, J.-J.; Poli, R., Organometallics 2009, 28, 4764-4777.

Chatt, J.; Wilkins, R. G., Nature (London, U. K.) 1950, 165, 859-60.

Plutino, M. R.; Otto, S.; Roodt, A.; Elding, L. I., Inorg. Chem. 1999, 38, 1233-1238.

Otto, S.; Roodt, A.; Elding, L. I., Inorg. Chem. Commun. 2006, 9, 764-766.

Chu, N. C. Hydroamination intermoléculaire des liaisons multiples carbone-carbone dans les solvants ioniques. Effet activant de $n$-Bu $\mathrm{Bu}_{4} \mathrm{PBr}$. Ph.D. Thesis, Université Paul Sabatier, Toulouse, 2005.

M. J. Frisch et al., Gaussian 03, Revision C.02, Gaussian, Inc., Wallingford CT 2004.

Becke, A. D., J. Chem. Phys. 1993, 98, 5648-5652.

Lee, C. T.; Yang, W. T.; Parr, R. G., Phys. Rev. B 1988, 37, 785-789.

Miehlich, B.; Savin, A.; Stoll, H.; Preuss, H., Chem. Phys. Lett. 1989, 157, 200-206.

Zhao, Y.; Truhlar, D. G., Acc. Chem. Res. 2008, 41, 157-167.

Roy, L. E.; Hay, P. J.; Martin, R. L., J. Chem. Theory Comput. 2008, 4, 1029-1031.

Barone, V.; Cossi, M., J. Phys. Chem. A 1998, 102, 1995-2001.

Cossi, M.; Rega, N.; Scalmani, G.; Barone, V., J. Comput. Chem. 2003, 24, 669-681.

Takano, Y.; Houk, K. N., J. Chem. Theory Comput. 2005, 1, 70-77.

Klamt, A.; Mennucci, B.; Tomasi, J.; Barone, V.; Curutchet, C.; Orozco, M.; Luque, F. J., Acc. Chem. Res. 2009, 42, 489-492.

Ho, J. M.; Coote, M. L., Theor. Chem. Acc. 2010, 125, 3-21.

Winget, P.; Cramer, C. J.; Truhlar, D. G., Theor. Chem. Acc. 2004, 112, 217-227.

Maseras, F.; Lledós, A., Computational Modeling of Homogeneous Catalysis. ed.;

Kluwer Academic Publishers: Dordrecht, The Netherlands, 2002.

Dub, P. A.; Poli, R., J. Mol. Catal. A 2010, 324, 89-96.

Henry, P. M., J. Am. Chem. Soc. 1964, 86, 3246-3250.

Henry, P. M., Adv. Chem. Ser. 1968, 126-154.

Anderson, C. B.; Burreson, B. J., Chem. Ind. 1967, 620.

Al-Najjar, I.; Green, M., Chem. Commun. 1977, 212-213.

Shaw, B. L., Chem. Commun. 1968, 464.

Hartley, F. R., Nature 1969, 223, 615-616.

Green, M.; Hancock, R. I., J. Chem. Soc. (A) 1967, 2054-2057.

Akermark, B.; Backvall, J. E.; Zetterberg, K., Acta Chem. Scand., Ser. B 1982, 36, $577-$ 585 .

Comas-Vives, A.; Stirling, A.; Lledos, A.; Ujaque, G., Chem. Eur. J. 2010, 16, 8738 8747.

Benedetti, E.; De Renzi, A.; Paiaro, G.; Panunzi, A.; Pedone, C., Gazz. Chim. Ital. 1972, $102,744-754$

Cowan, R. L.; Trogler, W. C., Organometallics 1987, 6, 2451-2453.

Kaplan, P. D.; Schmidt, P.; Orchin, M., J. Amer. Chem. Soc. 1968, 90, 4175-4176.

Panunzi, A.; De Renzi, A.; Palumbo, R.; Paiaro, G., J. Amer. Chem. Soc. 1969, 91, 38793883.

Hollings, D.; Green, M.; Claridge, D. V., J. Organometal. Chem. 1973, 54, 399-402.

Pesa, F.; Orchin, M., J. Organomet. Chem. 1976, 108, 135-8.

Al-Najjar, I. M.; Green, M., J. Chem. Soc., Chem. Commun. 1977, 926-927.

Sarhan, J. K. K.; Green, M.; Al-Najjar, I. M., J. Chem. Soc., Dalton Trans. 1984, 771777. 
Pryadun, R.; Sukumaran, D.; Bogadi, R.; Atwood, J. D., J. Am. Chem. Soc. 2004, 126, 12414-12420.

De Renzi, A.; Di Blasio, B.; Morelli, G.; Vitagliano, A., Inorg. Chim. Acta 1982, 63, 233-241.

Green, M.; Sarhan, J. K. K.; Alnajjar, I. M., J. Chem. Soc., Dalton Trans. 1981, 15651571 .

Green, M.; Sarhan, J. K. K.; Al-Najjar, I. M., Organometallics 1984, 3, 520-524.

Mcbee, J. L.; Tilley, T. D., Organometallics 2010, 29, 184-192.

Lorusso, G.; Barone, C. R.; Di Masi, N. G.; Pacifico, C.; Maresca, L.; Natile, G., Eur. J. Inorg. Chem. 2007, 2144-2150.

Wehmanooyevaar, I. C. M.; Grove, D. M.; Devaal, P.; Dedieu, A.; Van Koten, G., Inorg. Chem. 1992, 31, 5484-5493.

Seul, J. M.; Park, S., J. Chem. Soc., Dalton Trans. 2002, 1153-1158.

Utsunomiya, M.; Kuwano, R.; Kawatsura, M.; Hartwig, J. F., J. Am. Chem. Soc. 2003, 125, 5608-5609.

Bender, C. F.; Widenhoefer, R. A., J. Am. Chem. Soc. 2005, 127, 1070-1071.

Qian, H.; Widenhoefer, R. A., Org. Lett. 2005, 7, 2635-2638.

Al-Najjar, I. M.; Green, M.; Kerrison, S. J. S.; Sadler, P. J., J. Chem. Soc., Chem.

Commun. 1979, 311-312.

De Renzi, A.; Panunzi, A.; Vitagliano, A., Gazz. Chim. Ital. 1978, 108, 45-50.

Alnajjar, I. M.; Green, M.; Sarhan, J. K. K.; Ismail, I. M.; Sadler, P. J., Inorg. Chim. Acta 1980, 44, L187-L188.

Balacco, G.; Natile, G., J. Chem. Soc., Dalton Trans. 1990, 3021-3024.

Caulton, K. G., New J. Chem. 1994, 18, 25-41.

Crocker, C.; Errington, R. J.; Mcdonald, W. S.; Odell, K. J.; Shaw, B. L.; Goodfellow, R. J., Chem. Commun. 1979, 498-499.

Nemeh, S.; Jensen, C.; Binamira-Soriaga, E.; Kaska, W. C., Organometallics 1983, 2, 1442-1447.

Salem, H.; Shimon, L. J. W.; Leitus, G.; Weiner, L.; Milstein, D., Organometallics 2008, 27, 2293-2299.

Errington, R. J.; Mcdonald, W. S.; Shaw, B. L., J. Chem. Soc., Dalton Trans. 1982, 18291835.

Crocker, C.; Empsall, H. D.; Errington, R. J.; Hyde, E. M.; Mcdonald, W. S.; Markham, R.; Norton, M. C.; Shaw, B. L.; Weeks, B., J. Chem. Soc., Dalton Trans. 1982, $1217-$ 1224.

Grimm, J. C.; Nachtigal, C.; Mack, H. G.; Kaska, W. C.; Mayer, H. A., Inorg. Chem. Commun. 2000, 3, 511-514.

Gottker-Schnetmann, I.; White, P.; Brookhart, M., J. Am. Chem. Soc. 2004, 126, $1804-$ 1811.

Harlow, R. L.; Thorn, D. L.; Baker, R. T.; Jones, N. L., Inorg. Chem. 1992, 31, 993-997. Butler, D. C. D.; Bruce, D. W.; Lightfoot, P.; Cole-Hamilton, D. J., Can. J. Chem. 2001, 79, 472-478.

Dahlenburg, L.; Yardimcioglu, A., J. Organomet. Chem. 1985, 291, 371-386.

Albinati, A., et al., J. Am. Chem. Soc. 1993, 115, 7300-7312.

Vanderze, J. J.; Kennard, C. H. L., Z. Kristallogr. 1974, 139, 157-158.

Dub, P. A.; Rodriguez-Zubiri, M.; Baudequin, C.; Poli, R., Green Chem. 2010, 13921396.

Milstein, D., J. Am. Chem. Soc. 1982, 104, 5227-5228.

Crumpton, D. M.; Goldberg, K. I., J. Am. Chem. Soc. 2000, 122, 962-963.

Crumpton-Bregel, D. M.; Goldberg, K. I., J. Am. Chem. Soc. 2003, 125, 9442-9456.

Rudyi, R. I.; Solomentseva, A. I.; Cherkashina, N. V.; Evstaf'eva, O. N.; Salyn, Y. V.; Moiseev, I. I., Koord. Khim. 1976, 2, 499-506. 
Table of Contents Graphic

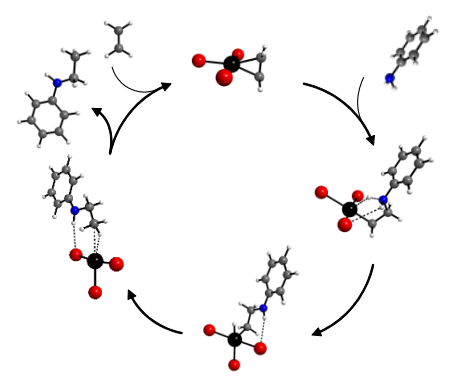

